\title{
X-ray CT and image analysis methodology for local roughness characterization in cooling channels made by metal additive manufacturing
}

\author{
Klingaa, C. G.; Dahmen, T.; Baier, S.; Mohanty, S.; Hattel, J. H.
}

Published in:

Additive Manufacturing

Link to article, DOI:

10.1016/j.addma.2019.101032

Publication date:

2020

Document Version

Peer reviewed version

Link back to DTU Orbit

Citation (APA):

Klingaa, C. G., Dahmen, T., Baier, S., Mohanty, S., \& Hattel, J. H. (2020). X-ray CT and image analysis methodology for local roughness characterization in cooling channels made by metal additive manufacturing. Additive Manufacturing, 32, [101032]. https://doi.org/10.1016/j.addma.2019.101032

\section{General rights}

Copyright and moral rights for the publications made accessible in the public portal are retained by the authors and/or other copyright owners and it is a condition of accessing publications that users recognise and abide by the legal requirements associated with these rights.

- Users may download and print one copy of any publication from the public portal for the purpose of private study or research.

- You may not further distribute the material or use it for any profit-making activity or commercial gain

- You may freely distribute the URL identifying the publication in the public portal 
1 X-ray CT and image analysis methodology for local

2 roughness characterization in cooling channels

3 made by metal additive manufacturing

5 C. G. Klingaa a, ${ }^{a}$, e-mail: cgkli@mek.dtu.dk. T. Dahmenª, e-mail: tdah@mek.dtu.dk. S.

6 Baier ${ }^{b}$, e-mail: sbaier@fysik.dtu.dk. S. Mohantya , e-mail: samoh@mek.dtu.dk.J.H.

$7 \quad$ Hattel $^{a}$, e-mail: jhat@mek.dtu.dk.

8 a Department of Mechanical Engineering, Technical University of Denmark,

9 Produktionstorvet, Building 425, 2800 Kgs. Lyngby, Denmark

10 b Department of Physics, Technical University of Denmark, Fysikvej, Building 307, 2800

11 Kgs. Lyngby, Denmark

$12{ }^{*}$ Corresponding author

14 Keywords

15 Powder bed fusion

16 Cooling channels

17 X-ray computed tomography

18 Image analysis

19 Roughness analysis

20

21 Declarations of interest: none. 


\section{Abstract}

25 The increasingly complex shapes and geometries being produced using additive manufacturing necessitate new characterization techniques that can address the corresponding challenges. Standard techniques for roughness and texture measurements are inept at characterizing the internal surfaces in freeform geometries. Hence, this work presents a new methodology for extracting and quantitatively characterizing the roughness on internal surfaces. The methodology links X-ray CT with complete roughness characterization of channels manufactured by laser powder bed fusion through a novel image analysis approach of X-ray CT data. Global and local orientation parameters are defined to enable a full $360^{\circ}$ description of the roughness inside additively manufactured channels. X-ray CT data is analyzed to generate 3D deviation data - based on which multiple local roughness profiles are extracted and analyzed in accordance with the ISO 4287:1997 standard. To demonstrate the proposed methodology, seven circular 17-4 PH stainless steel channels produced at different inclinations and with a diameter of $2 \mathrm{~mm}$ are investigated as a case study. Qualitative and quantitative characterization of the roughness is obtained through the use of the proposed methodology. A strong dependence of the local roughness on the corresponding $\alpha$ and $\beta$ orientations is found. A simple regression model is subsequently extracted from the calculated roughness values and allows prediction of Ra-values in the channels for the ranges between $0^{\circ} \leq \alpha \leq 90^{\circ}$ and $80^{\circ} \leq \beta \leq 280^{\circ}$. In addition to decreasing the effective hydraulic diameter of a cooling channel, the surface roughness also influences the local Nusselt number, which is quantified using the extracted regression model.

\section{Introduction}

Metal additive manufacturing (AM) is getting increasingly incorporated in the industry as an advanced manufacturing technology. A major advantage of $A M$ is the possibility of manufacturing components with complex freeform designs. The production of components with integrated cooling channels has become an active field of application for AM. Conformal cooling channels in injection molds (enabled by AM) have shown 
decreased cycle time, reduced residual stresses and greater control of the cooling process [1-3] as compared to conventional cooling channel designs. However, conformal cooling channels produced with the laser powder bed fusion (LPBF) process still face challenges such as the presence of high internal surface roughness.

The two primary modes for the high internal surface roughness generation identified in the literature are the staircase effect and the dross formation at downward facing surfaces $[4,5]$. The staircase effect is a well-known issue seen in many layer-by-layer additive manufacturing practices and is directly related to the layer height and the discrete partitioning of the slicing conducted prior to the manufacturing process [6]. The roughness at overhanging areas results from partial melting/sintering of nearby powder particles during the processing of each layer by the laser [7]. The partial melting/sintering is accentuated in the case of overhanging areas as the significantly lower conductivity of the powder bed compared to the bulk material causes localized heat accumulation [8]. Several works in the literature have focused on investigating the influence of LPBF process parameters (e.g. laser power, hatch spacing, and scanning speed) on the roughness observed at overhanging areas $[9,10]$.

As the presence of high internal surface roughness is an inherent product of the LBPF process, post-processing steps are often necessary to remove these rough features thus resulting in higher costs and increased lead time for AM components. Moreover, depending on the geometrical complexity of the channels, the efficacy of the postprocessing methods in removing the internal roughness can be quite low. Consequently, specific design rules have been developed in the literature for addressing this issue of roughness in cooling channels e.g. changing the circular crosssection of the channels into a teardrop shape [11]. This design compensation approach has been shown to result in near-circular channel cross-sections for specific orientations of the cooling channels. However, the generic implementation of this approach requires a reasonable estimation of the expected roughness at different channel locations. Moreover, general design rules may also be found in standards such as the VDI 3405 Part 3 [12]. This standard provides guidelines for positioning and part orientation in order to minimize roughness and the need for support structures. Unfortunately, these 
guidelines can not be fully applied to conformal cooling channels where the aim is to increase heat transfer and in most cases, all orientations will be present. Thus, the capability of performing a detailed characterization of the internal surface roughness is an important step towards an accurate design for metal AM manufactured cooling channels.

\subsection{Characterization of surface texture}

The application of areal roughness parameters defined in ISO 25178-2:2012 [13] is gaining momentum for additively manufactured components. Specifically, the combination of X-ray Computed Tomography (X-ray CT) with dimensional metrology and areal surface characterization is increasingly seen $[7,14,15]$ and efforts are being made towards the development of methodologies and software solutions that combine the capabilities of X-ray CT with roughness analysis [16]. These efforts are particularly relevant for internal surface characterization of freeform shapes where standard planar techniques for surface topography measurements (such as the stylus profilometer) cannot easily be used [17]. In comparison, X-ray CT allows for internal measurements of dimensions and roughness, which is particularly useful for AM components [18]. The $\mathrm{X}$-ray CT technique is less influenced by the complexity of the geometrical design and offers a nondestructive visualization of the internal features [19]. Furthermore, the X-ray CT technique does not suffer from the inability to detect steep slopes and undercuts as the standard optical methods [20]. Other areas where X-ray CT are applied for engineering purposes are within the characterization of agglomerates of primary particles $[21,22]$. This area could be relevant for metal AM components due to the characteristic dross formation seen at overhanging areas consisting of sintered particles $[5,7]$.

For the case of classic profile measurements, roughness tolerances are typically verified according to the ISO 4288:1997 standard [23] by applying either the max rule or the $16 \%$ rule. This standardized procedure builds on the assumption that an adequate description of the surface texture can be generated through 12 randomly distributed 
113 measurements. However, such as assumption is not valid for LPBF manufactured 114 components due to the orientation dependence of the local surface roughness. Thus, 115 there is a need for tools that enable complete characterization of the roughness of LPBF 116 manufactured surfaces.

\subsection{Roughness and cooling ability of channels}

The need for accurate characterization of internal surfaces of cooling channels becomes even more evident considering the influence of the roughness on the flow behavior of the coolant. First, the flow in channels is directly influenced by the actual diameter of the channel and by the presence of internal design features e.g. ribs, corrugations and bends $[24,25]$. The effect of the build orientation on the actual crosssectional area of LPBF channels has been investigated in [26]. It was found that the actual cross-sectional area decreased in an almost linear manner when comparing seven LPBF channels built with inclinations going from perpendicular to the build direction to parallel with the build direction. This effect will directly influence the actual hydraulic diameter of a channel. Dross material emerging from the LPBF process can not only reduce the effective diameter of these channels but also modify the effective design of the internal features such as ribs and dimples. Furthermore, the high localized roughness in LPBF manufactured channels may also emulate internal design features such as corrugations or ribs.

The cooling ability of these channels is typically described through the Nusselt number [11], which is a dimensionless parameter comparing the heat transfer over the fluid/wall interface to the heat transfer through the fluid itself [27]. The direct influence of roughness on the Nusselt number can be described by the Gnielinski equation [28]:

$$
\mathrm{Nu}_{\mathrm{D}}=\frac{\frac{\mathrm{f}}{8}\left(\operatorname{Re}_{\mathrm{D}}-1000\right) \operatorname{Pr}}{1+12.7\left(\frac{\mathrm{f}}{8}\right)^{1 / 2}\left(\operatorname{Pr}^{2 / 3}-1\right)}
$$

Where Pr is the Prandtl number, Re is the Reynolds number and $f$ is called the friction factor. The friction factor $f$ is directly related to the roughness of the channel and can be 
140 found by utilizing the Moody Diagram [29]. By knowing the relative roughness $\varepsilon$ / D

141 (where $\varepsilon$ is the sand grain roughness of the channel and $D$ is the diameter) and the Red

142 for the flow, the friction factor may be read out from the Moody diagram. Equation (1) is

143 valid for a fully developed flow over a large Res range including the transitional area

$144\left(3000 \leq \operatorname{ReD} \leq 5 \times 10^{6}\right)$, while other such relationships exist for a non-developed or

145 developing flow.

146 When taking into account the friction factor as shown in equation (1), the influencing 147 roughness is the roughness along the direction of flow in the channels - implying that

148 areal surface texture parameters such as Sa are not useful as measurands. A linear

149 relationship between $\mathrm{Ra}$ and Sa for surfaces without directional features is suggested in

150 the literature [30], while other works caution against interpreting the similar magnitudes

151 of the two quantities as a linear correlation [31]. Due to the complex shapes of

152 conformal cooling channels, a full description of the surface roughness is necessary in

153 order to accurately model the cooling ability of such channels.

\section{1.3 Purpose of the current work}

156 The overall goal of this paper is to create a link between X-ray CT data and local 157 roughness characterization by using image analysis. The link is made by the proposal of 158 a methodology for obtaining a full characterization of the internal surface roughness of 159 channels produced by LPBF. The purpose of the methodology is to enable the 160 generation of simple models for the prediction of local roughness at any point on the 161 surface inside metal AM channels, as shown in Fig. 1.

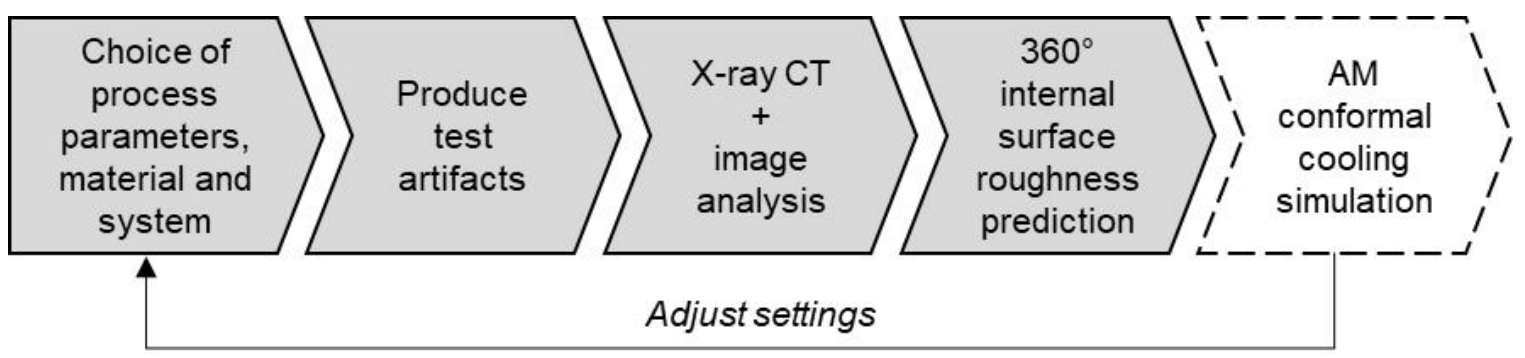

$\square$ Scope of this work I_I Future work

Figure 1: Purpose and scope of the present work. 
162 The generated models could then be used for predicting the surface roughness of 163 channels produced on the same system, using the same process parameters, in the 164 same material, and in similar dimensions as the test artifacts used for creating the 165 models. Adjusting settings regarding the process parameters, the material or the LPBF 166 system requires a repetition of the procedure. As may be seen in Fig. 1, performance 167 simulations of conformal cooling channels are seen as a future application of the $360^{\circ}$ 168 internal surface roughness prediction.

169 It is not the intention of the paper to challenge existing standards. Instead, the paper 170 intends to develop a useful tool for the designing phase of additively manufactured 171 cooling channels for cooling critical components such as injection molds and 172 microsystems.

\section{Material and methods}

175 In this work, the internal surface roughness of LBPF manufactured channels is evaluated in terms of the classic profile roughness parameters according to the ISO 4287:1997 standard [32]. The methodology is an extension of the prior work by Klingaa et. al [33] on characterizing the areal roughness of conformal cooling channels by using $X$-ray CT along with an in-house developed Python image analysis tool. The current methodology uses 3D point cloud deviation data and describes the internal surface texture of a straight channel in terms of deviations from a nominal geometry. Then, the methodology extracts roughness profiles at every angle around the channel by innovatively implementing an angular criterion and a distance criterion that allows identification of the channel direction. The current work also introduces two orientation notations for metal AM manufactured channels, namely the global orientation and the local orientation. After the detailed surface characterization, biharmonic interpolation and polynomial fitting methods are utilized to generate a surface prediction model of $\mathrm{Ra}$ roughness as a function of both the global and the local orientation. Subsequently, the obtained surface prediction model is used to determine the effect of local roughness on the local friction factor and subsequently the local Nusselt number. 
191 In the following subsections, the investigated test artifacts, the X-ray CT data acquisition 192 procedure, the data analysis methods, the image analysis based profile extraction 193 methodology, the procedure for generating simple surface prediction models for the 194 local roughness and the application of the developed models for assessing the effect on 195 the local Nusselt number are described in more detail.

\subsection{Investigated components}

198 As a case study, seven 17-4 PH stainless steel cuboids manufactured on an EOS M 199 290 system were investigated in this work. The cuboids of dimensions $12.5 \mathrm{~mm} \times 10$ $\mathrm{mm} \times 10 \mathrm{~mm}$ (height, width, length) were built within the same build job, and have not received any post-processing treatment (such as sand-blasting). The seven investigated cuboids are shown in Fig. 2(a) while the chosen process parameters are shown in Table 1. Each of the cuboids has an internal channel of $2 \mathrm{~mm}$ diameter inclined at a particular angle to the build direction. The investigated inclination angles (henceforth called the 205 global orientation $\alpha$ ) corresponded to $\alpha=0^{\circ}, 15^{\circ}, 30^{\circ}, 45^{\circ}, 60^{\circ}, 75^{\circ}$, and $90^{\circ}$ as seen in 206 Fig. 2(b).

207 Table 1: Process parameters for larger build job.

\begin{tabular}{|l|l|}
\hline Process parameter & Value \\
\hline Laser power, $P_{L}$ & $220.1 \mathrm{~W}$ \\
\hline Scanning speed, $v_{\text {scan }}$ & $755.5 \mathrm{~mm} / \mathrm{s}$ \\
\hline Hatch spacing, $\Delta y_{\text {hatch }}$ & $110 \mu \mathrm{m}$ \\
\hline Layer height, $\Delta$ zlayer $_{\text {lat }}$ & $40 \mu \mathrm{m}$ \\
\hline Spot diameter, $d_{\text {spot }}$ & $100 \mu \mathrm{m}$ \\
\hline Particle size & $\mathrm{D} 50: 36-44 \mu \mathrm{m}$ \\
\hline
\end{tabular}




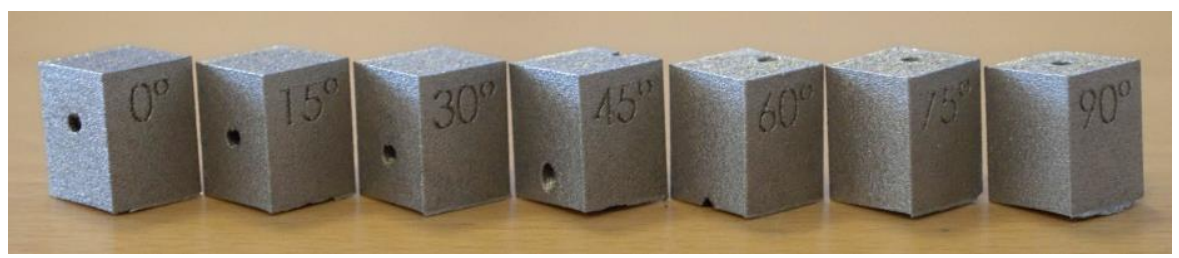

(a) The seven investigated cuboids with internal channels with different global orientations.

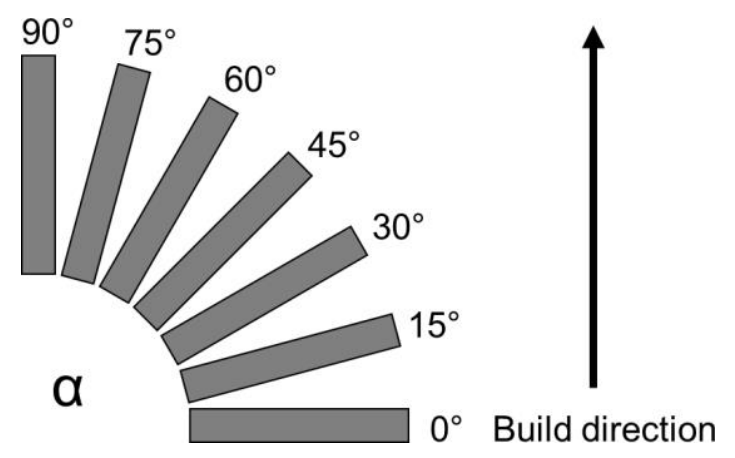

(b) The global orientation $\alpha$.

Figure 2: (a) The investigated cuboids. (b) Description of the global orientation $\alpha$.

\section{$210 \quad 2.2 \mathrm{X}$-ray CT and image analysis preparation}

211 The X-ray CT scans were conducted using a Nikon XT H 225 ST system with a cone

212 beam setup and a flat panel detector. Each artifact was scanned once with the same

213 optimized scanning parameters. The X-ray tomograms were obtained using a tungsten

214 filament and a $0.5 \mathrm{~mm}$ Sn filter with a voltage of $220 \mathrm{kV}$ and power of $29.9 \mathrm{~W}$. Each of

215 the 1571 projections was acquired using an exposure time of $t=1 \mathrm{~s}$ and two frames

216 were averaged per projection. With two-by-two binning, a volume with an effective pixel

217 size of $15.9 \mu \mathrm{m}$ was obtained. The 3D cone beam reconstruction was conducted with

218 the X-Tek CT Pro 3D software (Nikon Metrology Inc.) using filtered-back projection

219 resulting in a voxel size of $15.9 \mu \mathrm{m}$. 
220 The reconstructed volumes were individually realigned in Avizo 9.2 to present a cross-

221 sectional view of the channel in each case (as shown in Fig. 3(a)). For each of the

222 seven reconstructed volumes, a stack consisting of 1000 TIFF images was generated

223 with a 1000 pixels by 1000 pixels resolution. Using ImageJ, the image stacks were

224 cropped to contain the channel and a small surrounding area of the material only, as

225 can be seen in Fig. 3(b). The resulting resolution of the cropped cross-sectional views

226 was approximately 150 pixels by 150 pixels.

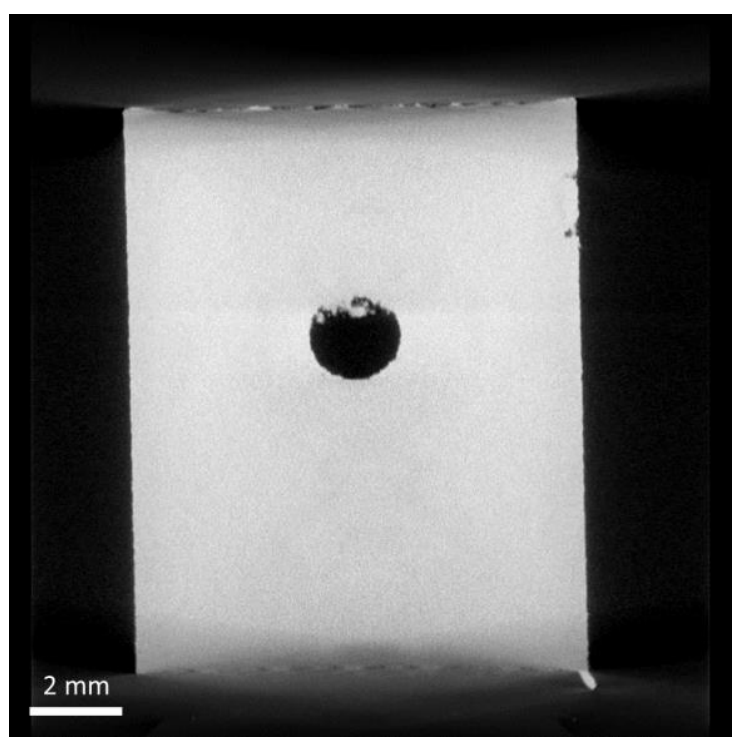

(a) Original cross-sectional view.

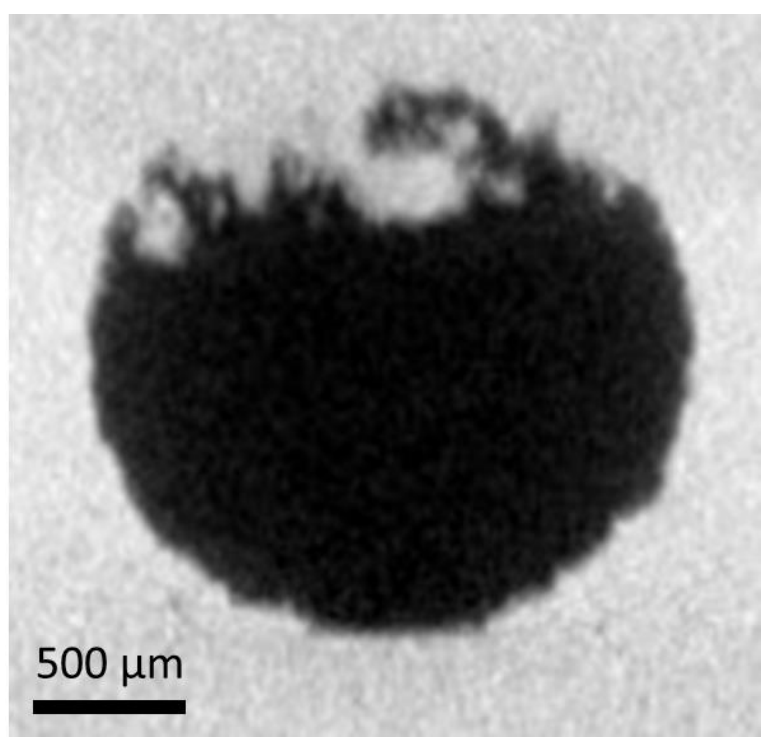

(b) Cropped cross-sectional view.

Figure 3: (a) Post-realignment generated TIFF cross-sectional image. (b) Cropped image of (a).

The quality of the CT scans around the exits of the channels was not as sharp as those for the interior regions of the cuboid. Furthermore, the different lengths of the channels due to different global orientations created a challenge for comparison of the different image stacks. Consequently, only the middle 500 slices of each image stack were used to represent the corresponding channel. Thus, all investigated channels within this work were represented by a corresponding stack of 500 images, with a resolution of 150 pixels by 150 pixels and a voxel size of $15.9 \mu \mathrm{m}$. 


\subsection{Method of analysis}

237 The thickness of each image slice was equal to the voxel size of $15.9 \mu \mathrm{m}$, with the stack of images corresponding to an overall length of approximately $8 \mathrm{~mm}(=15.9 \mu \mathrm{m} / \mathrm{slice} x$ 500 slices). The stacks were imported into an in-house Python code that generated 3D point cloud deviation data by computing the distance from each vertex in the meshed CT reconstructed surface to a nominal fitted geometry. The 3D point cloud deviation data was subsequently loaded into a second in-house Python code to extract roughness

243 profiles along the length of the channels.

\subsubsection{Deviation analysis}

246 The deviation analysis was conducted using a methodology proposed by Klingaa et al

247 [33]. The steps of the methodology (illustrated in Fig. 4) can be described as follows:

1. Image segmentation ImageJ, and an average threshold value is extracted per stack based on all the corresponding 500 images.

\section{Mesh generation} The original image stack and the computed threshold value are imported into an in-house Python code which isolates the internal geometry of each image and generates a mesh using the Lewiner's marching cubes method [34]

3. Nominal geometry creation

A fitted-ellipse approach is followed to create the nominal geometry from the meshed surface representing the actual internal geometry of the channel.

4. Deviation data computation

The nominal geometry is compared to the meshed surface to create a set of 3D point cloud deviation data. 


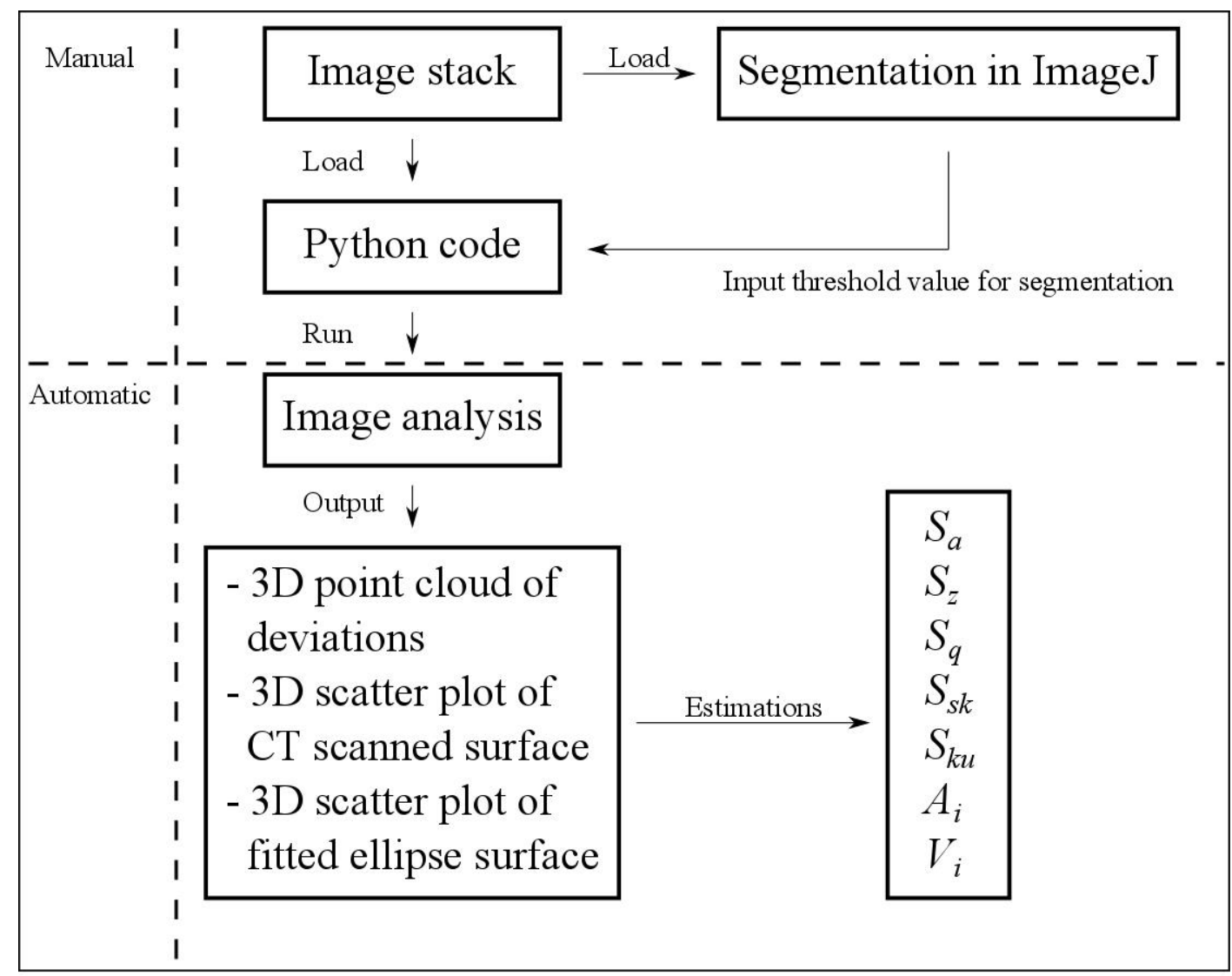

Figure 4: Analysis steps in the proposed methodology from [33].

263 The 3D deviation point cloud data can be used to generate a 3D scatter plot for each

264 channel. The scatter plot for the channel produced at $\alpha=0^{\circ}$ is shown as an example in

265 Fig. 5. The figure shows the meshed surface together with the deviation values

266 recorded at each vertex of the mesh. The in-house Python code also generated surface

267 texture characteristics according to ISO 25178-2:2012, but this information was not

268 used in this work. The aforementioned deviation analysis was repeated for each of the

269 seven stacks of images and generated seven sets of 3D point cloud deviation data. 


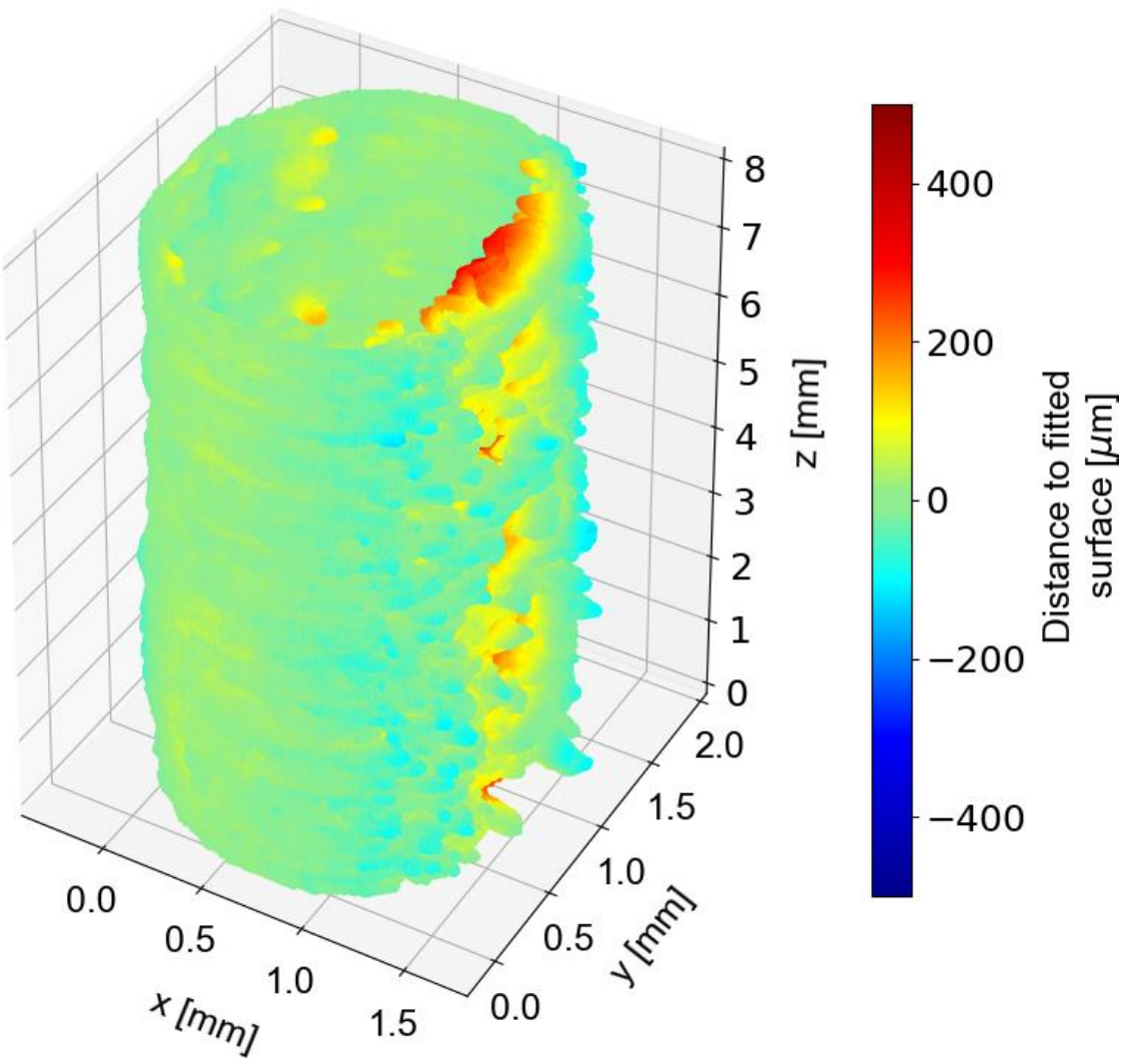

Figure 5: 3D scatter plot of the resulting deviation analysis of the channel produced at $\alpha=0^{\circ}$.

\subsubsection{Profile extraction methodology}

272 A methodology for extracting profiles out of the sliced deviation data was developed

273 based on a bottom-up approach, wherein the profiles were generated by tracking a line

274 through the vertices of the respective mesh according to set criteria. The methodology

275 involved the following steps (illustrated in Fig. 6):

- Identification of centerline (see Fig. 6(1)): A linear fit of the center points of each data slice along the z-direction is used to identify the centerline for the channel. The centerline determined the overall direction for the extracted profiles and the reference points for determining the local orientation and angular distances within the channel.

- Seed \& dummy point generation (see Fig. 6(2a) and 6(3a)): Each of the vertices in the bottom slice (i.e. at $n=0$ in Fig. 6(2a)) was used as seeds for generating the different profiles. A dummy point was generated in each slice at the 
intersection of the respective slice with a vector passing through the seed point and parallel to the centerline.

- Angular criteria check (see Fig. 6(2b)): All points in the same slice were considered as potential points for representing the profile in that specific slice. The dummy point for the slice represented the optimal angular position of the next point and was used for an angular test. The angular test identified all potential points in the slice that was within a prescribed angle (set to $5^{\circ}$ in this work) with respect to the centerline and the dummy point.

- Deviation distance check (see Fig. 6(2c)): When at least 1 point passed the angular criterion, the deviation distances of the passing points were checked. The deviation distance for each point was already obtained from the procedure described in section 2.3.1. The point with the maximum positive deviation was then chosen as the point representing the profile in that slice, ensuring that points that were close to the centerline (i.e. points with high deviation) were captured.

The described procedure was repeated through all 500 slices until a complete profile had been extracted from the 3D deviation data, as sketched in Fig. 6(4). An example of a single generated profile is shown in Fig. 7. The procedure was repeated for all the seed points until a complete $360^{\circ}$ description of the surface was generated- resulting in more than 500 profiles around the periphery of the channel for each of the seven investigated channels. A combined view of all the profiles generated from the 3D deviation data for the channel with $\alpha=0^{\circ}$ is shown in Fig. 8, and can be compared with the point cloud in Fig. 5 to show the efficiency of the profile extraction methodology. 


\begin{tabular}{|c|c|c|}
\hline $\begin{array}{l}\text { (1) Define the centerline } \\
\text { (CL) }\end{array}$ & $\begin{array}{l}\text { (2a) Create dummy point } \\
\text { in the next n-layer }\end{array}$ & $\begin{array}{l}\text { (2b) Check angle } \\
\text { deviations }\end{array}$ \\
\hline$\left\{\begin{array}{c}1 \\
\vdots \\
1 \\
\vdots\end{array}\right.$ & 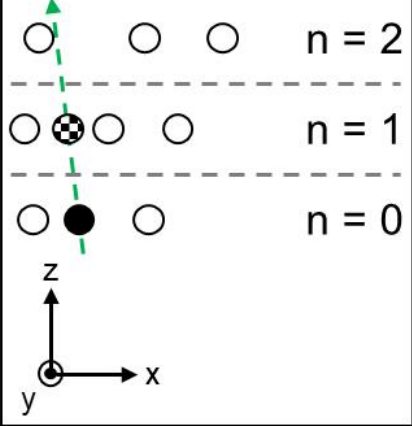 & $\underset{y}{\mathrm{z}}$ \\
\hline $\begin{array}{l}\text { (2c) Check deviations } \\
\text { from nominal shape }\end{array}$ & $\begin{array}{l}\text { (3a) Create dummy point } \\
\text { in the next n-layer }\end{array}$ & $\begin{array}{l}\text { (4) Repeat process a-b- } \\
\text { c through all n-layers }\end{array}$ \\
\hline$\underset{\downarrow}{\mathrm{z}} \underset{\mathrm{x}}{\mathrm{x}}$ & 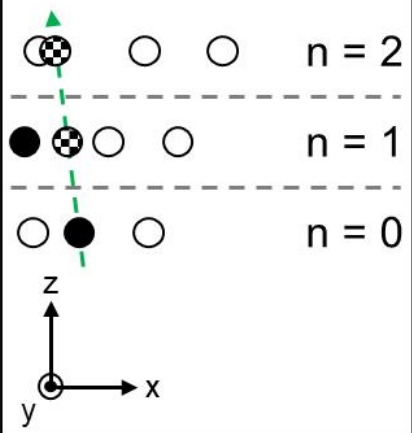 & $\int_{y}^{z}$ \\
\hline line & my point & or \\
\hline
\end{tabular}

Figure 6: Stepwise procedure for generating a profile from the 3D deviation data.

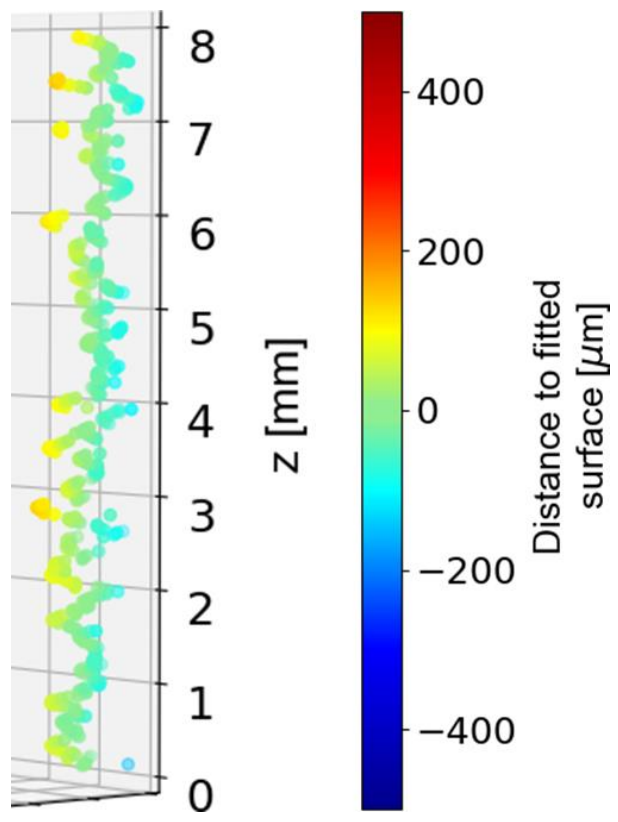

Figure 7: Single profile generated bottom-up from 3D deviation data shown in Fig. 5 $\left(\alpha=0^{\circ}\right)$. 


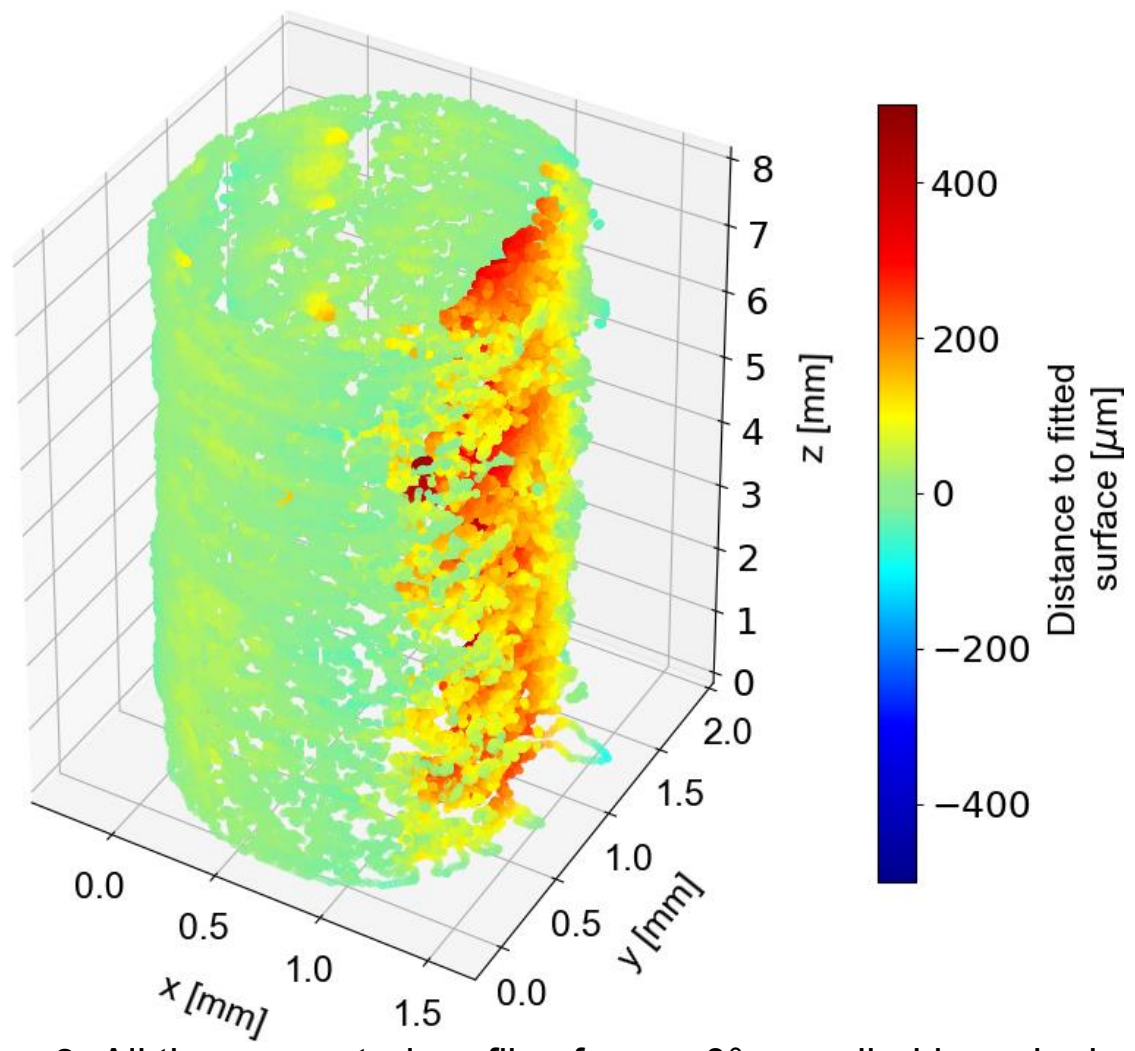

Figure 8: All the generated profiles for $\alpha=0^{\circ}$ compiled in a single plot.

\subsubsection{Profile roughness calculations}

To analyze the roughness of the channel, the arithmetical mean height (or Ra) of each profile was calculated separately according to ISO 4287:1997:

$$
\mathrm{Ra}=\frac{1}{\mathrm{l}} \int_{0}^{\mathrm{l}}|\mathrm{Z}(\mathrm{x})| \mathrm{dx}
$$

311 where $I$ is the sampling length of the investigated profile and $Z(x)$ is the corresponding

312 height value for each $\mathrm{x}$-value. Other parameters such as the root mean square value $\mathrm{Rq}$

313 or the maximum height of a profile Rz could also be used to evaluate the roughness in

314 the channel, but Ra was selected for this study because it is often compared to sand

315 grain roughness [35]. Since the roughness investigation in this work had a focus on

316 functionality, the evaluation length and sampling lengths according to the ISO standard

317 were not explicitly followed. Instead, the profile was leveled and a least squares fitting

318 line was subsequently subtracted from the profile. The modified profile was used for 
319

321

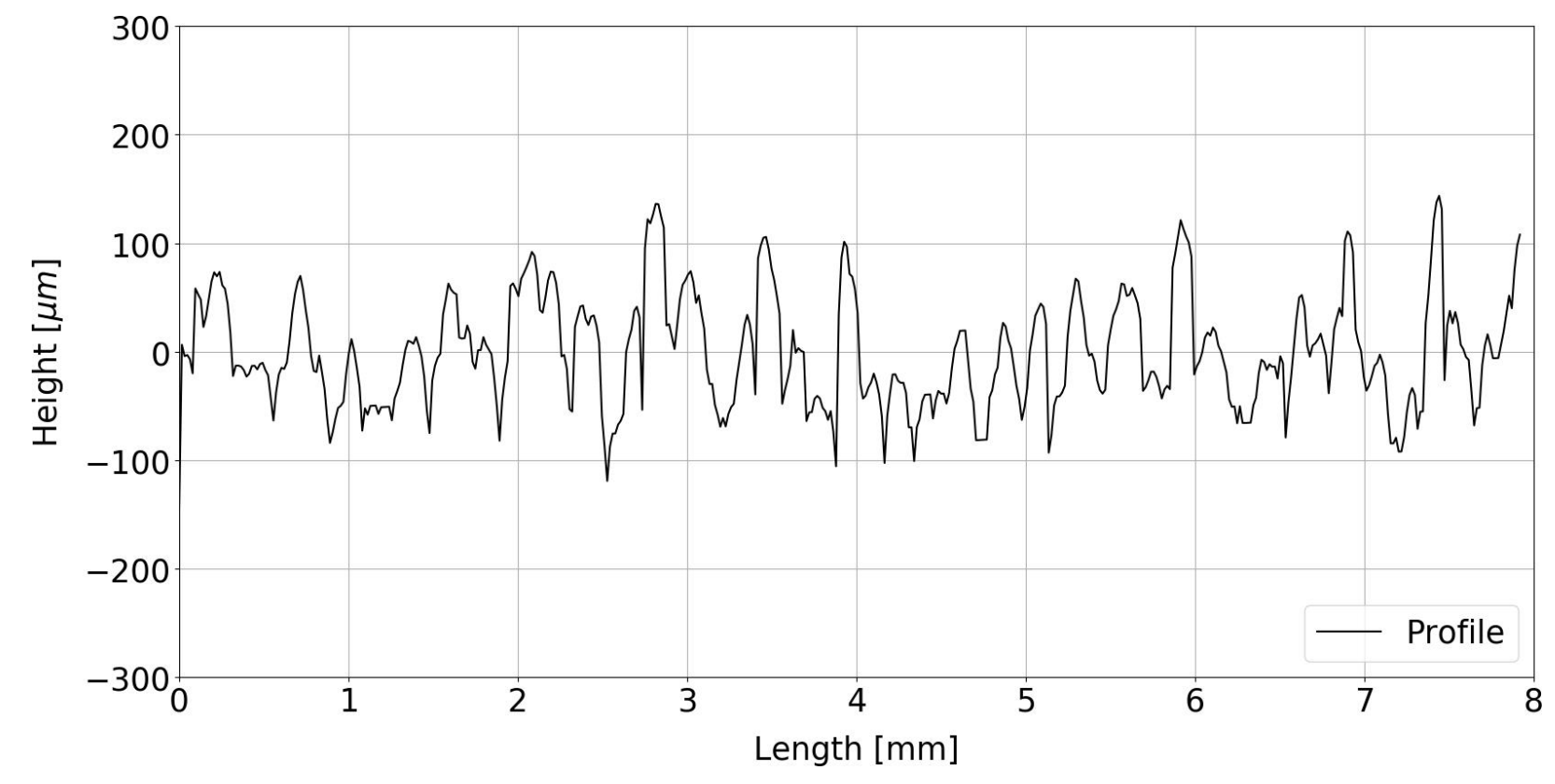

Figure 9: Classic representation of a profile. The profile has been leveled and a least squares fitting line has been subtracted from the profile for subsequent $\mathrm{Ra}$ calculation. The profile corresponds to the extracted profile shown in Fig. 7. calculating a corresponding Ra-value. Fig. 9 shows a classic representation of a profile corresponding to the generated profile in Fig. 7.

323 The Ra calculation was performed for all the generated profiles for each of the seven 324 channels. Since more than 500 profiles had been obtained for each channel, a map of 325 Ra-values was obtained with respect to the local orientation within each channel 326 (henceforth known as $\beta$ ) as illustrated in Fig. 10. To ensure comparability between 327 channels, an alignment procedure was followed by selecting the 40 largest Ra-values

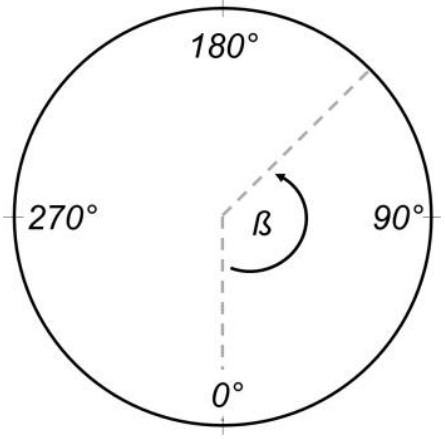

Figure 10: Definition of the local orientation $\beta$. 
328 and finding their mean value. The local orientation with an Ra-value closest to this mean

329 value was then identified, and the entire Ra map was rotated such that the local

330 orientation became $\beta=180^{\circ}$. Such alignment procedure was driven by the assumption

331 that the highest roughness values should correspond to the overhanging area of the

332 channel, around $\beta=180^{\circ}$ with respect to Fig. 10. As an example, the Ra as a function

333 of the local orientation $\beta$ for the channel built with the global orientation $\alpha=0^{\circ}$ is shown

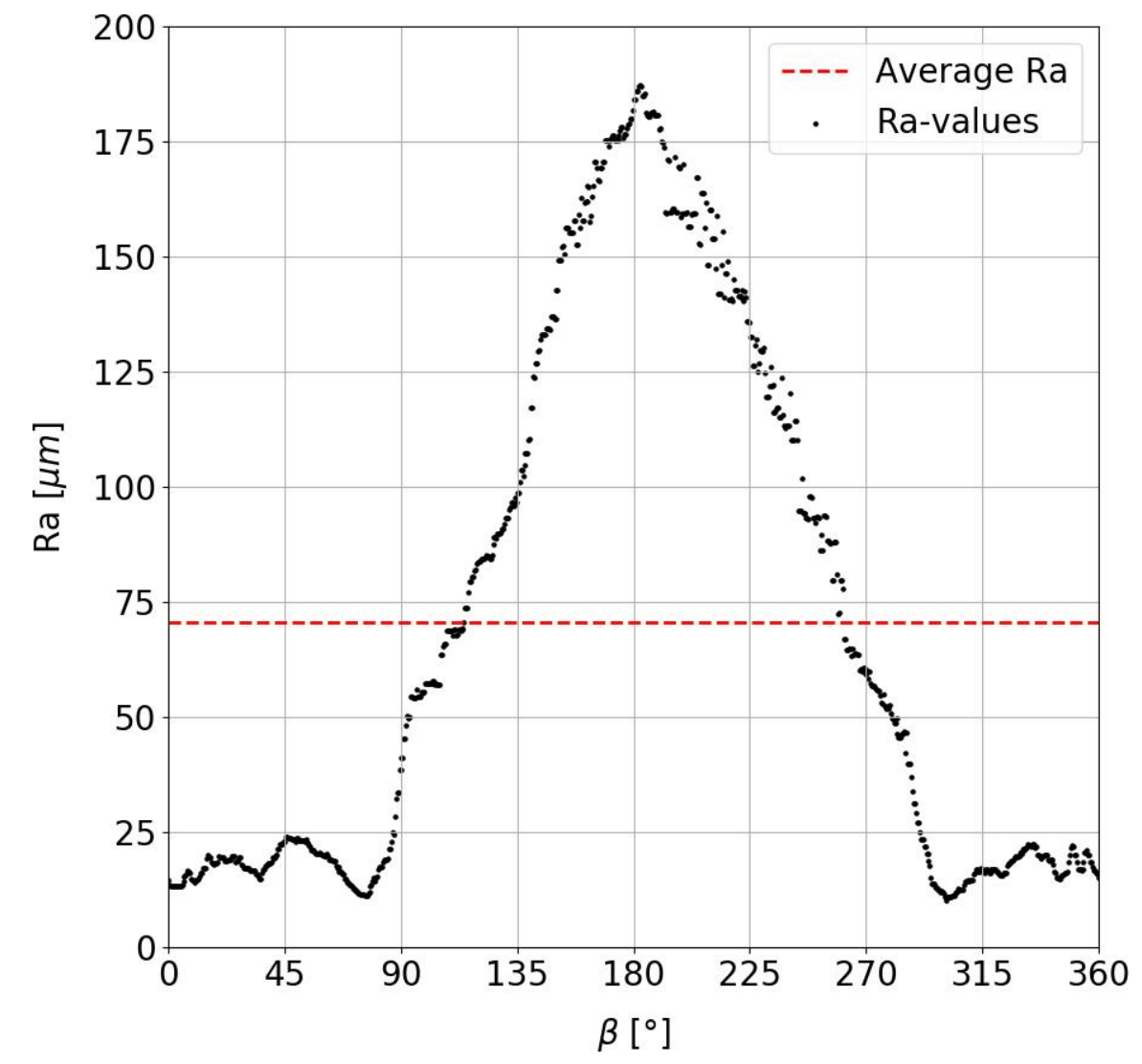

Figure 11: Ra as function of the local orientation $\beta$ for the channel produced with global orientation $\alpha=0^{\circ}$.

334 in Fig. 11. The red dashed line in Fig. 11 shows the overall average of the calculated 335 Ra-values.

\subsection{Prediction models}

338 The estimated Ra-values as a function of both $\alpha$ and $\beta$ were exported from the in-house Python code and loaded into MATLAB. In order to generate response surface models 
340 for the internal roughness of the investigated channels, MATLAB's Curve Fitting Tool

341 was used. The Ra-values were set as the " $Z$ data", the $\alpha$-values were set as the " $Y$

342 data", and the $\beta$-values were set as the " $X$ data". First, a model based on an

343 interpolated fit was created using the Interpolant option and Biharmonic (v4) method

344 with no center and scaling. Second, two models based on a polynomial fit were created

345 using the Polynomial option. The degrees for the " $X$ data" and the " $Y$ data" were

346 manually selected to minimize the complexity of the model equations while ensuring

347 good fits. The Robust option was off and no center and scaling was used.

\section{$348 \quad 2.6$ Friction factor and Nusselt number}

349 As a further case study, one of the obtained response surface prediction models was

350 used to evaluate the effect of local roughness on the local Nusselt number. As

351 mentioned in Section 1.2, the friction factor may be estimated by utilizing the Moody

352 Diagram [36], as shown in Fig. 12. For the current investigation, a fully developed flow

353 with $R_{D}=20000$ was assumed. Furthermore, the Ra-values calculated in this work

354 were assumed to correspond to the sand grain roughness $\varepsilon$. The relative roughness

$355 \varepsilon / D=R a / D$ could subsequently be calculated with a channel diameter of $D=2 \mathrm{~mm}$,

356 allowing the friction factor to be determined directly from Fig. 12. For the calculation of

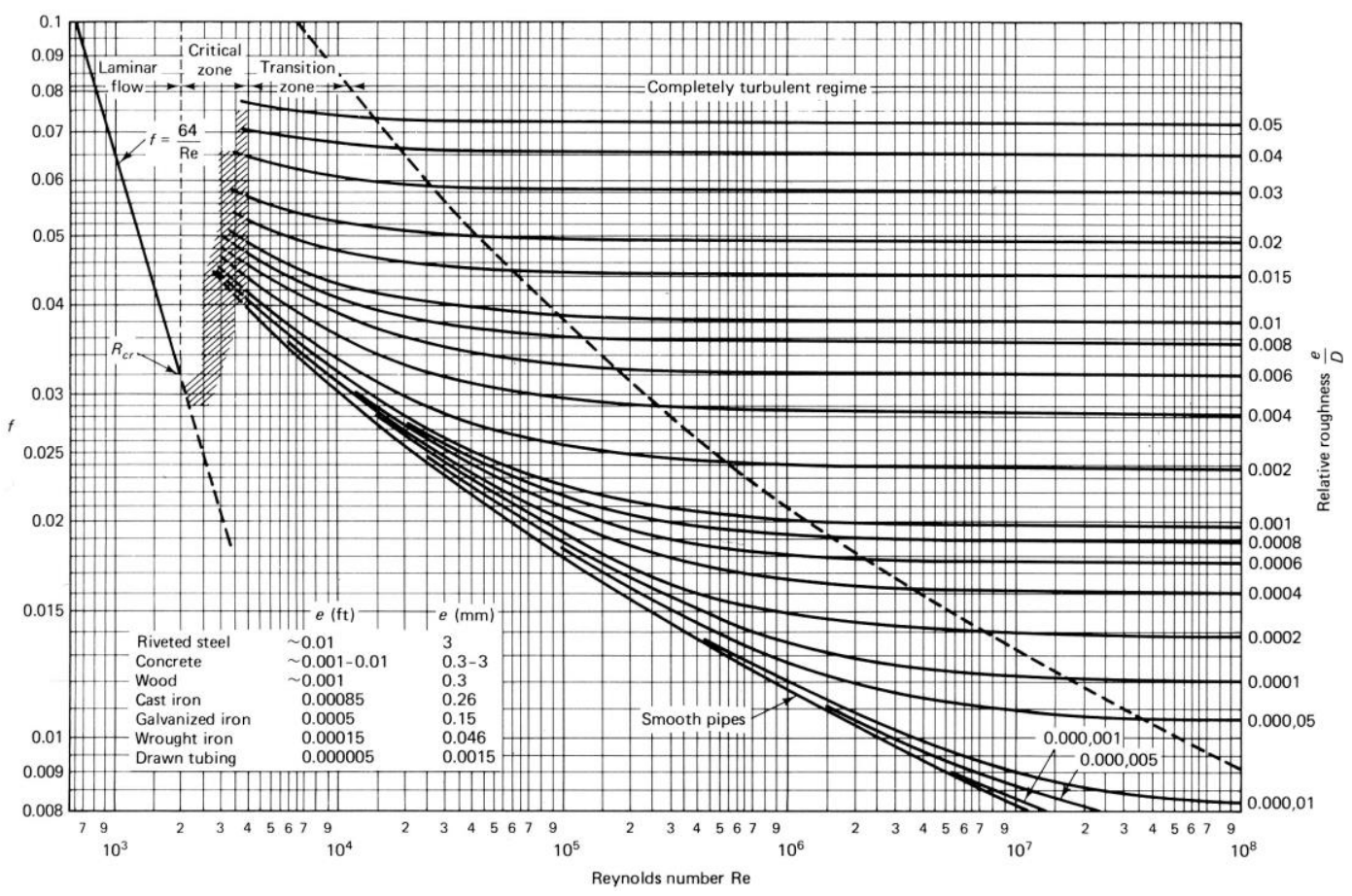

Figure 12: Moody Diagram [36]. 
357 the Nusselt number, equation (1) was utilized. The cooling fluid was assumed to be

358 water at $50^{\circ} \mathrm{C}$, resulting in an approximate Prandtl number of $\operatorname{Pr}=3.55$ [37].

\section{Results and discussion}

361 In this section, the results obtained by applying the methodology described in Section 2 362 on the seven investigated channels are presented and discussed. The section includes 363 results and discussions in terms of graphical representations of the analyzed channels, $364 \mathrm{Ra}$ as a function of the global orientation, $\mathrm{Ra}$ as a function of both the global orientation 365 and the local orientation, surface prediction modeling of $\mathrm{Ra}$ as a function of global and 366 local orientation and the influence of the local roughness on the local Nusselt number.

\subsection{Graphical representations of the channel roughness}

369 The first step, as discussed in Section 2.3.1, was to analyze all seven CT scanned 370 channels by generating a 3D point cloud deviation data set for each of the channels.

371 The resulting deviation point clouds are visualized in Fig. 13. The deviation data for the 372 channels shown in Fig. 13 was normalized such that the color bar was representative 373 for all seven channels. 


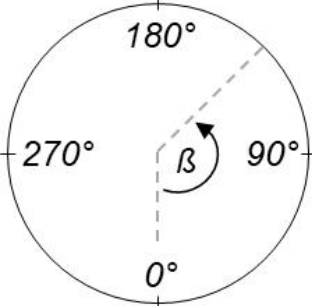

Example: $\beta=135^{\circ}$

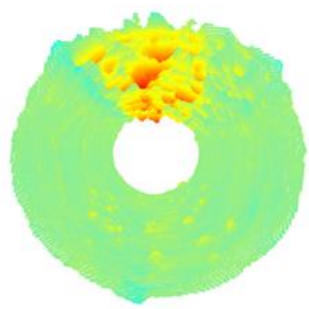

$\alpha=45^{\circ}$

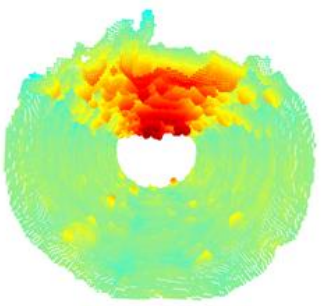

$\alpha=0^{\circ}$

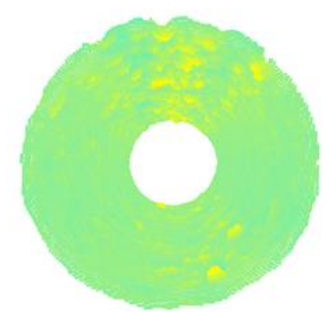

$\alpha=60^{\circ}$

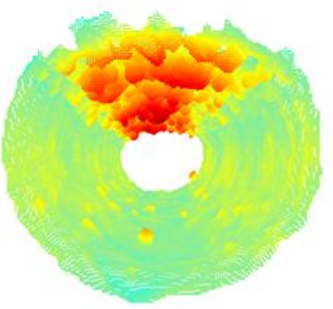

$\alpha=15^{\circ}$

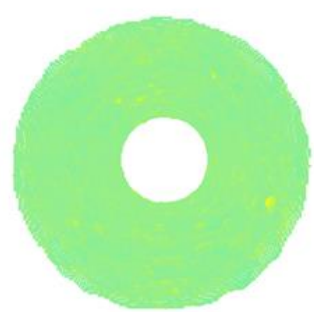

$\alpha=75^{\circ}$

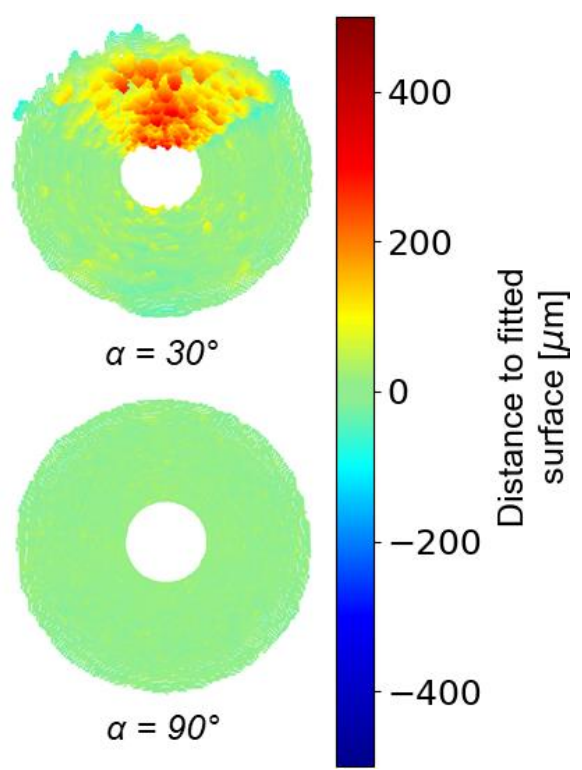

$\alpha=90^{\circ}$

Figure 13: Through view of the channels, visualizing the roughness dependency on the location inside a channel (the local orientation $\beta$ ) and build direction (the global orientation $\alpha$ ).

375 The comparison shows that the global orientation $\alpha$ influences the overall obtained

376 roughness. The roughness is highest between $\alpha=0^{\circ}$ and $\alpha=15^{\circ}$ while decreasing

377 towards $\alpha=90^{\circ}$. The difference observed between $\alpha=90^{\circ}$ and $\alpha=75^{\circ}$ is small and will

378 be discussed in further detail later in this section. Apart from the direct influence of the

379 global orientation, the influence of orientation $\beta$ on the local roughness can also be observed. While the roughness is generally highest at around $\beta=180^{\circ}$ for all channels due to the alignment procedure described in Section 2.3.3, a clear pattern can be observed at other local orientations except for the two channels corresponding to $\alpha=$ $75^{\circ}$ and $\alpha=90^{\circ}$.

384 The performed surface characterization indicated a systematic influence of the global 385 and the local orientation on the observed roughness. Specifically, for $\alpha=0^{\circ}, 15^{\circ}, 30$, $38645^{\circ}$ and $60^{\circ}$, the following general observations can be made:

- First, the roughness is rapidly increasing at specific $\beta$-values. This can be interpreted as a belt of high roughness at the overhanging area. 
- Second, the upward facing surface shows tracks of higher roughness at around $\beta=45^{\circ}$ and $\beta=315^{\circ}$, which is especially noticeable for $\alpha=0^{\circ}$ and $\alpha=15^{\circ}$. A possible explanation could be the sintering of particles to the surface. However, the LPBF process typically induces sintered particles at overhanging areas and not upward facing surfaces, and therefore the exact cause/mechanism is currently unknown.

- Third, the large roughness can be observed to effectively reduce the crosssectional area along the entire channels, especially at low $\alpha$-values.

\subsection{Ra as a function of the global orientation}

With the 3D point clouds readily available, the extraction of roughness profiles and the subsequent calculation of Ra-values were conducted. The resulting mean and standard deviations of Ra-values calculated from the extracted roughness profiles are shown in Fig. 14 with the mean-values following the $t$-distribution. For the sake of simplicity, and due to the shape of the interpolation observed in Fig. 14, a polynomial modeling approach was chosen in this work as a first step towards generating a prediction model. Fitting a third degree polynomial to the observed mean values yielded:

$$
R a_{\text {mean }}=\left(0.0002 \times \alpha^{3}-0.0257 \times \alpha^{2}-0.3629 \times \alpha+73.012\right) \mu m
$$

with an $R^{2}=0.980$. The issue with this procedure was that the polynomial fit only described the overall expected mean roughness of the channel as a function of $\alpha$, but could not account for the large standard deviations at low $\alpha$-values. The large standard deviations observed were directly related to the influence of the local orientation $\beta$ at the specific global orientation $\alpha$, and the funnel-like reduction towards higher $\alpha$-values indicated a loss of influence from the local orientation $\beta$. 


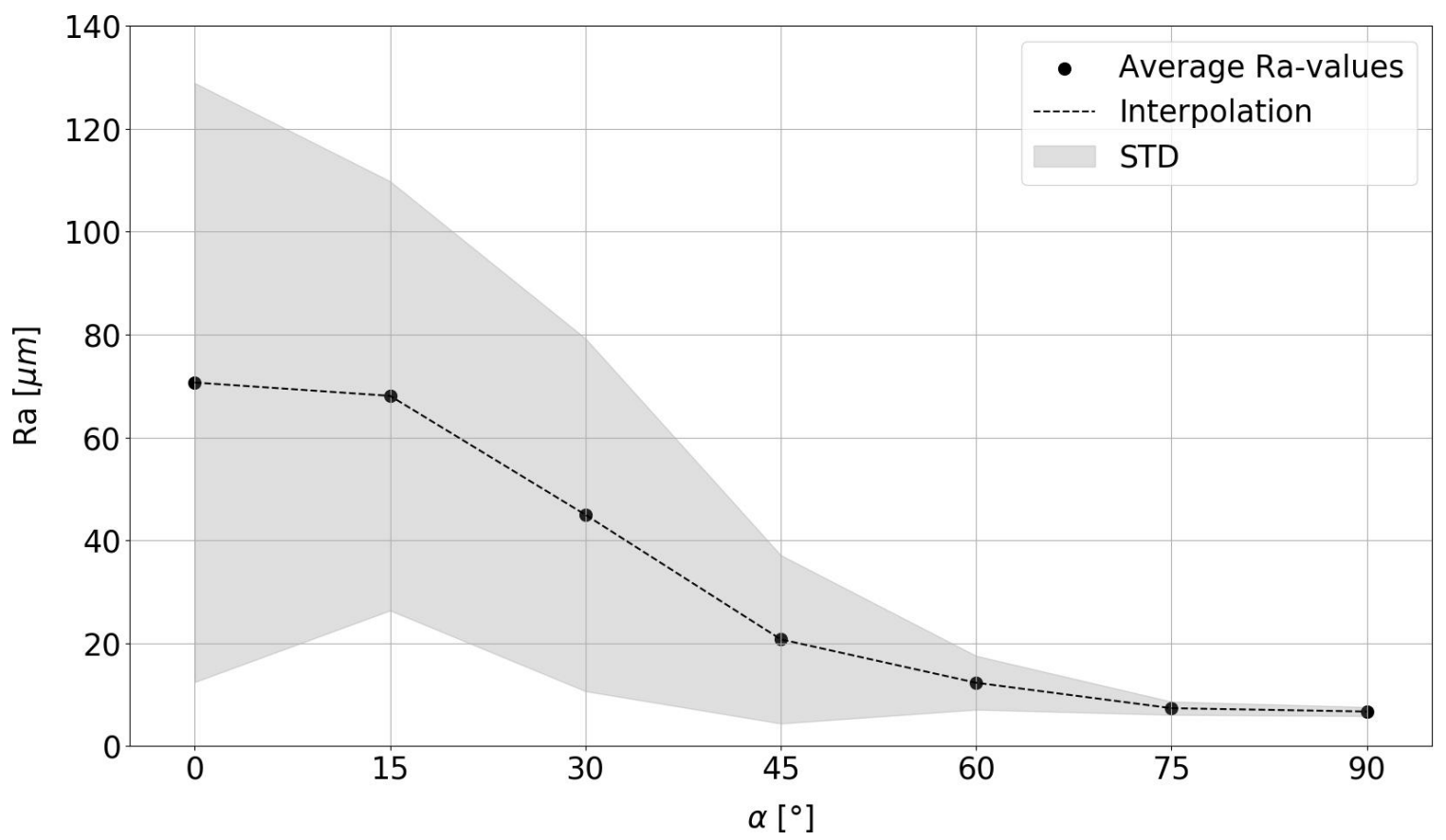

Figure 14: Mean Ra as a function of the global orientation $\alpha$, with the corresponding standard deviations marked by the shaded region.

\section{$418 \quad 3.3 \mathrm{Ra}$ as a function of the global and the local orientations}

419 While Fig. 14 showed the average of the calculated Ra-values, Fig. 15 shows a more 420 detailed view of the calculated Ra-values at each $\beta$-angle and for each $\alpha$-angle. As

421 mentioned in Section 2.3.3, the Ra-results were rotated for each of the channels such 422 that the highest $R a$ is around $\beta=180^{\circ}$. As a result, the individual surface graphs were 423 approximately symmetrically aligned.

424 The belts of high roughness, previously mentioned in Section 3.1, can be more easily 425 visualized in Fig. 15. For quantification purposes, the rough belt for each channel was 426 assumed to begin where the Ra-values continuously increase towards the maximum 427 Ra-value, and the determined angular widths are shown in Table 2. It must be noted 428 that the rough belts visualized in Fig. 13 are smaller than the widths captured with this 429 assumption. 
430 Due to the low magnitude of measured roughness values, the belt could not be 431 identified for the $\alpha=75^{\circ}$ and $\alpha=90^{\circ}$ channels. The low measured roughness is

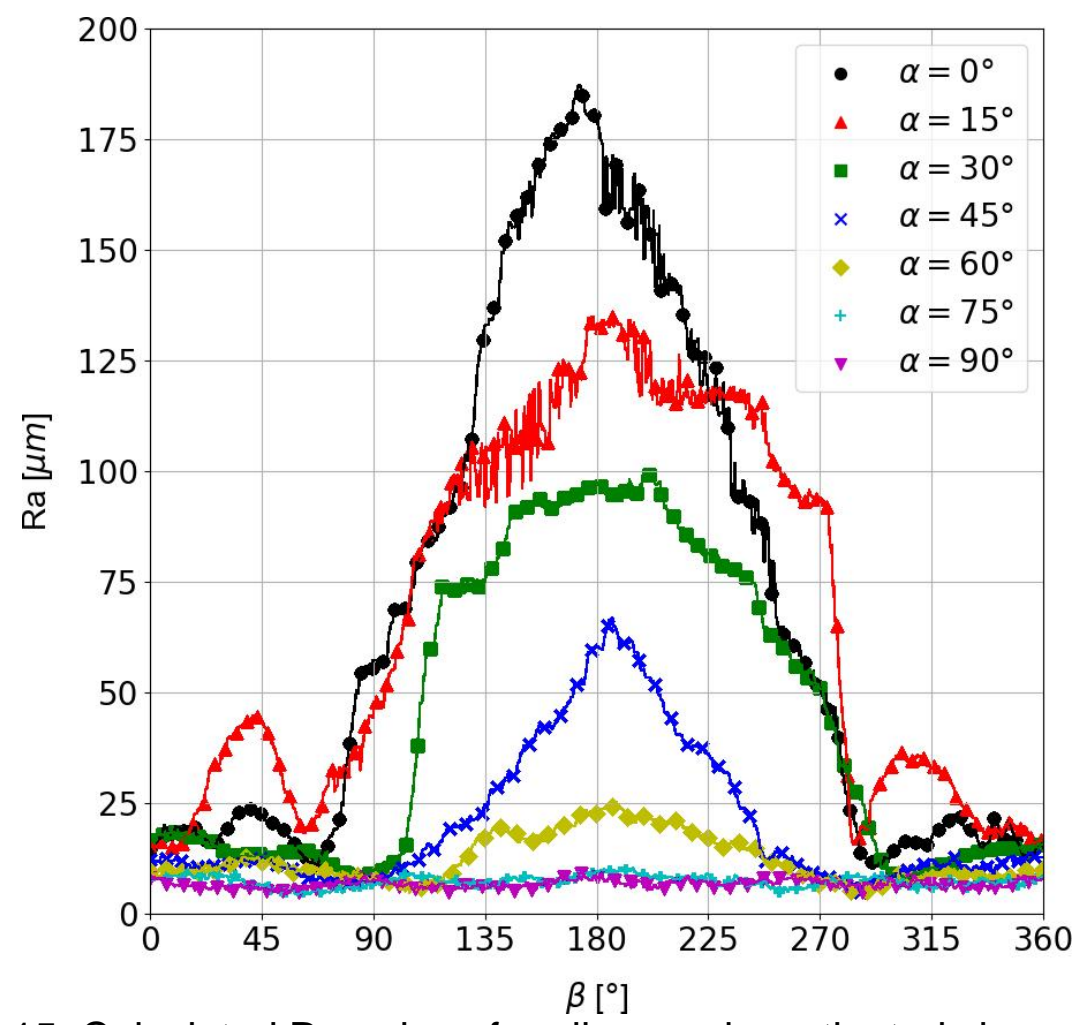

Figure 15: Calculated Ra-values for all seven investigated channels as a function of the local orientation $\beta$.

432 hypothesized to be caused by the obtained voxel size of the CT-scans. A large voxel

433 size $(\sim 15.9 \mu \mathrm{m})$ puts a direct limitation on the detected surface and leads to an

434 underestimation of the actual Ra-values $[38,39]$. This emphasizes the importance of

435 thoroughly considering the design of the investigated components, such that a low voxel

436 size may be obtained and the most common surface features detected [40]. For the

437 current study, the voxel size was found adequate since the considered roughness was

438 significantly larger than the voxel size in most of the investigated channels.

439 Table 2: $\beta$-range and angular width of rough belt observed at the overhanging area.

\begin{tabular}{|l|l|l|}
\hline $\boldsymbol{\alpha}\left[^{\circ}\right]$ & Range: $\boldsymbol{\beta}_{1} \leq \boldsymbol{\beta} \leq \boldsymbol{\beta}_{2}\left[^{\circ}{ }^{\circ}\right]$ & Angular width $\left[^{\circ}\right]$ \\
\hline 0 & $77.5 \leq \beta \leq 292.5$ & 215 \\
\hline 15 & $77.5 \leq \beta \leq 287.5$ & 210 \\
\hline
\end{tabular}




\begin{tabular}{|l|l|l|}
\hline 30 & $105 \leq \beta \leq 297.5$ & 192.5 \\
\hline 45 & $102.5 \leq \beta \leq 250$ & 147.5 \\
\hline 60 & $120 \leq \beta \leq 250$ & 130 \\
\hline 75 & $\% \leq \beta \leq \%$ & NA \\
\hline 90 & $\% \leq \beta \leq \%$ & NA \\
\hline
\end{tabular}

440 Fig. 16 shows the same Ra-values in an inverse polar plot enabling an intuitive

441 representation of the results wherein the magnitude of the Ra-values and their

442 distribution can be compared to the actual surfaces observed in Fig. 13.

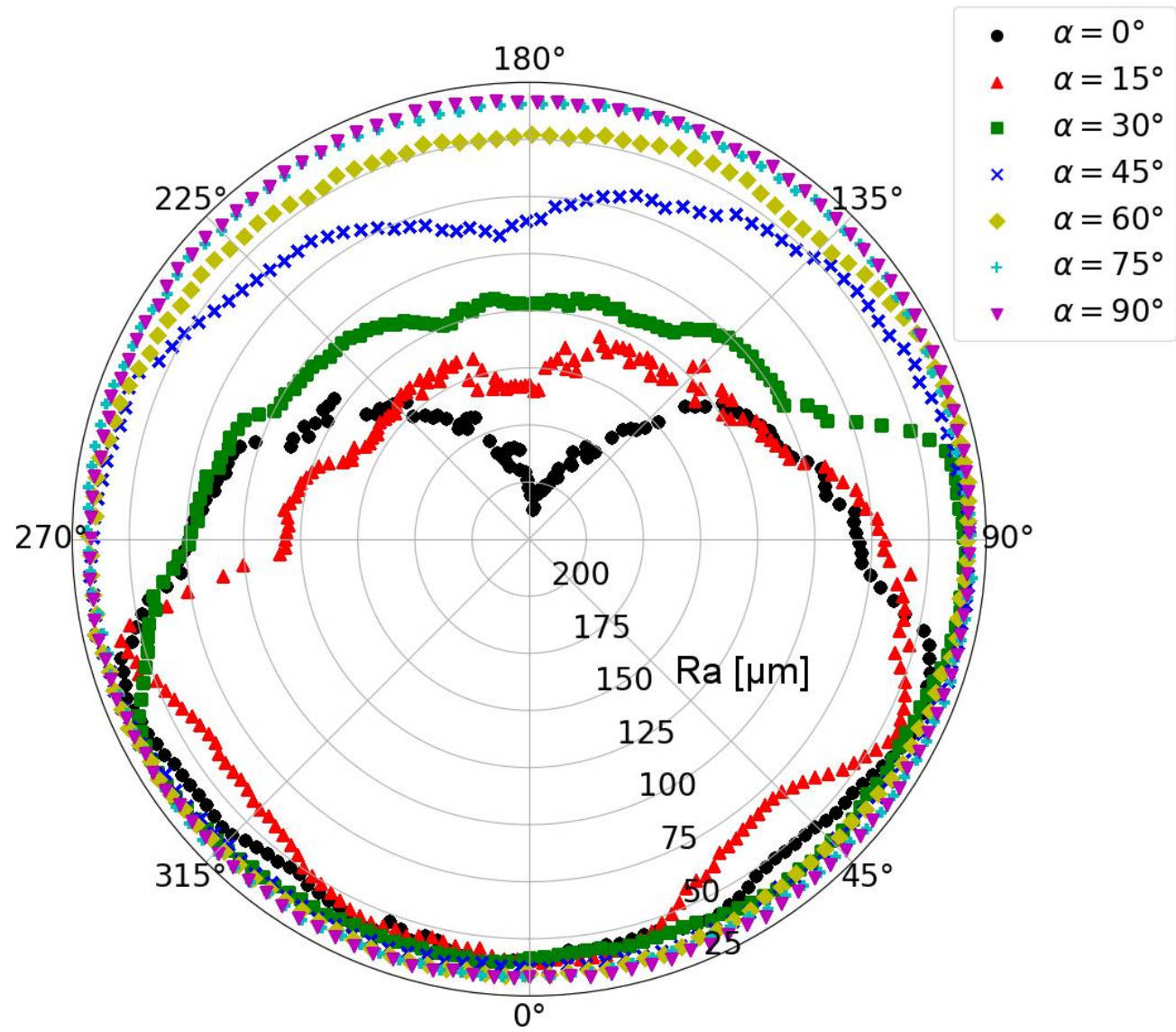

Figure 16: Inverse polar plot of the calculated Ra-values for all investigated channels as a function of the local orientation $\beta$. 
445 Fig. 13 indicates a higher roughness at approximately $\beta=45^{\circ}$ and $\beta=315^{\circ}$ for both the $446 \alpha=0^{\circ}$ and $\alpha=15^{\circ}$ channels. This indication is confirmed in both Fig. 15 and Fig. 16

447 where the rough areas result in medium sized 'bumps' on both the graphs for $20^{\circ} \leq \beta \leq$ $44860^{\circ}$ and $280^{\circ} \leq \beta \leq 320^{\circ}$. These bumps could be related to the staircase effect, an 449 inherent roughness effect observed for layered manufacturing processes. The staircase 450 effect decreases with increasing $\alpha$; hence, the worst-case scenario has been 451 investigated in Fig. 17.

452 A layer height of $40 \mu \mathrm{m}$ corresponding to the process parameters shown in Table 1, 453 and a channel diameter of $D=2 \mathrm{~mm}$ was considered for the $\alpha=0^{\circ}$ case. At

454 approximately $\beta=17^{\circ}$, the largest theoretical step-induced protrusion is observed after 455 which the protrusions go towards zero as $\beta$ approaches $90^{\circ}$. As the staircase effect can 456 contribute with up to $38 \mu \mathrm{m}$, it is possible that the observed protruding bumps could 457 have been induced by the staircase effect together with other influencing factors. One 458 such influencing factor could be agglomerated powder particles fitting into the gaps 459 observed between the protrusions at these angles. Such agglomerated particles may in 460 fact be seen in Fig. 13 for $\alpha=0^{\circ}$ and $\alpha=15^{\circ}$ at approximately $\beta=45^{\circ}$ and $\beta=315^{\circ}$. 461 The staircase effect also diminishes for higher $\alpha$-values, which is also confirmed by the 462 reduction in the size of the bumps in Fig. 15 and Fig. 16 until the effect is no longer 463 visible at $\alpha=45^{\circ}$. 


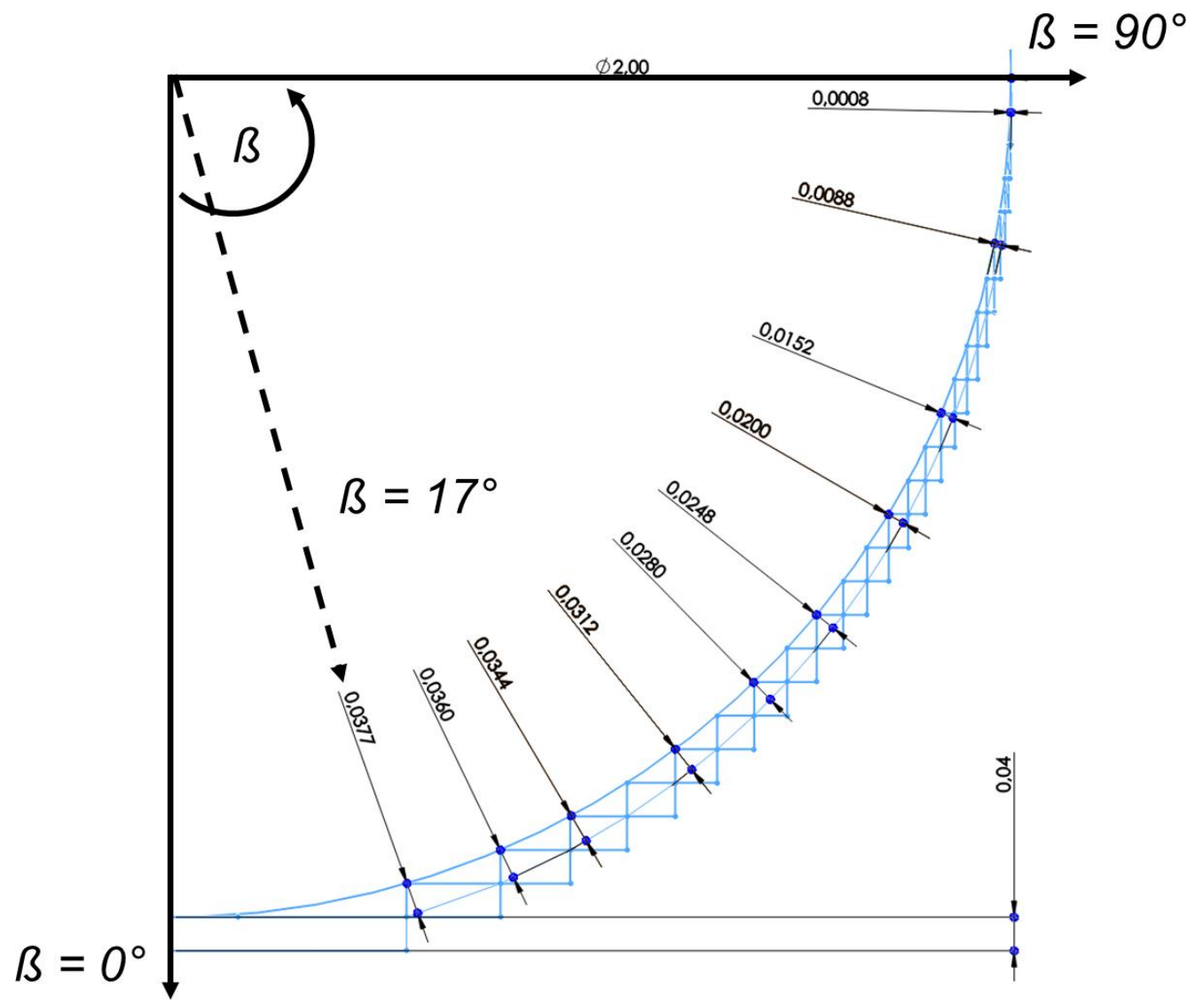

Figure 17: Sketch showing the worst-case scenario of the staircase effect for $\alpha=0^{\circ}$. The noted dimensions are in $\mathrm{mm}$.

$466 \quad 3.4$ Main limitations of the surface characterization method

467 While the method captures and extracts profiles from 3D point cloud data adequately, 468 some limitations of the technique can be identified. These limitations are connected to 469 the voxel size of the reconstructed CT scanned component (already discussed in 470 Section 3.3), the mesh density, and the assumptions regarding the angular criterion.

471 The analysis was based on imported meshes representing the actual reconstructed CT 472 scanned geometries. The point densities of these meshes had a direct influence on the

473 straightness of the extracted profiles as sketched in Fig. 6. Even with a fully dense 474 mesh, the distribution and density of vertices were in the end limited by the obtained 475 voxel size. 
A narrower angular criterion would have produced profiles more accurately representing the true profile at the specified angle. A broad angular criterion was chosen in order to ensure that the analysis would always find at least 1 point that fulfilled the set angular criterion. A more accurate procedure would be to set an initial angular criterion to a lower value $\left(\right.$ e.g. $\left.1^{\circ}\right)$ and implement an incrementally increasing angular criterion until at least one point is identified. This was not implemented in the current work due to limitations in computational power, as the in-house Python code was developed with the purpose of being run on a standard laptop within a reasonable time.

\subsection{Simple prediction models for local roughness}

In this section, the experimentally determined Ra-values are used to create a response surface model based on the global orientation $\alpha$ and the local orientation $\beta$. Capturing this dependency would allow for prediction of the expected Ra-value at any point within a cooling channel produced on the same system, using the same process parameters, the same material, and in similar dimensions as the channels used for generating the model.

To begin, an interpolation model was utilized to generate a visual representation of the expected Ra-values for the $\alpha$ - and $\beta$-ranges investigated. Fig. 18 shows a surface plot and a contour plot of a biharmonic interpolation of the experimental data as a function of $\alpha$ and $\beta$. This interpolation can be used to visually predict the expected Ra-values at any given global and local orientation. Although the visual predictions made with this model were closely related to the measured results, a model equation could not be produced. This meant that utilization of the model for other modeling purposes, such as cooling performance, was not ideal.

As an alternative solution, a polynomial model was fitted to the Ra-results and the corresponding surface plot and contour plot can be seen in Fig. 19. The fitted polynomial was of the fourth degree and was visually optimized to fit the Ra-results. The corresponding response surface model equation was: 
$505 \quad R a(\alpha, \beta)=-40.15+2.866 \times \alpha+1.872 \times \beta-0.1074 \times \alpha^{2}-0.03573 \times \alpha \times \beta-$

$5060.005227 \times \beta^{2}+0.001674 \times \alpha^{3}+0.0001077 \times \alpha^{2} \times \beta+0.0001077 \times \alpha \times \beta^{2}-8.503 \times$

$50710^{-6} \times \alpha^{4}+5.526 \times 10^{-7} \times \alpha^{3} \times \beta+5.264 \times 10^{-7} \times \alpha^{2} \times \beta^{2}$

508

509 The equation (3) above predicts the $\operatorname{Ra}(\alpha, \beta)$ output in $\mu \mathrm{m}$ but has been written without 510 units for brevity. The fitting approach resulted in an $R^{2}$ of 0.802 . As seen in Fig. 19(a),

511 the surface does not capture the extremes of the Ra curves. This is also clearly seen

512 from the contour plot depicted in Fig. 19(b). The polynomial fit resulted in an

513 underestimation of the maximum Ra-values observed for $\alpha=0^{\circ}$ by over $30 \%$.

514 Furthermore, the amount of coefficients in the resulting equation is not satisfactory

515 considering the poor fit. 


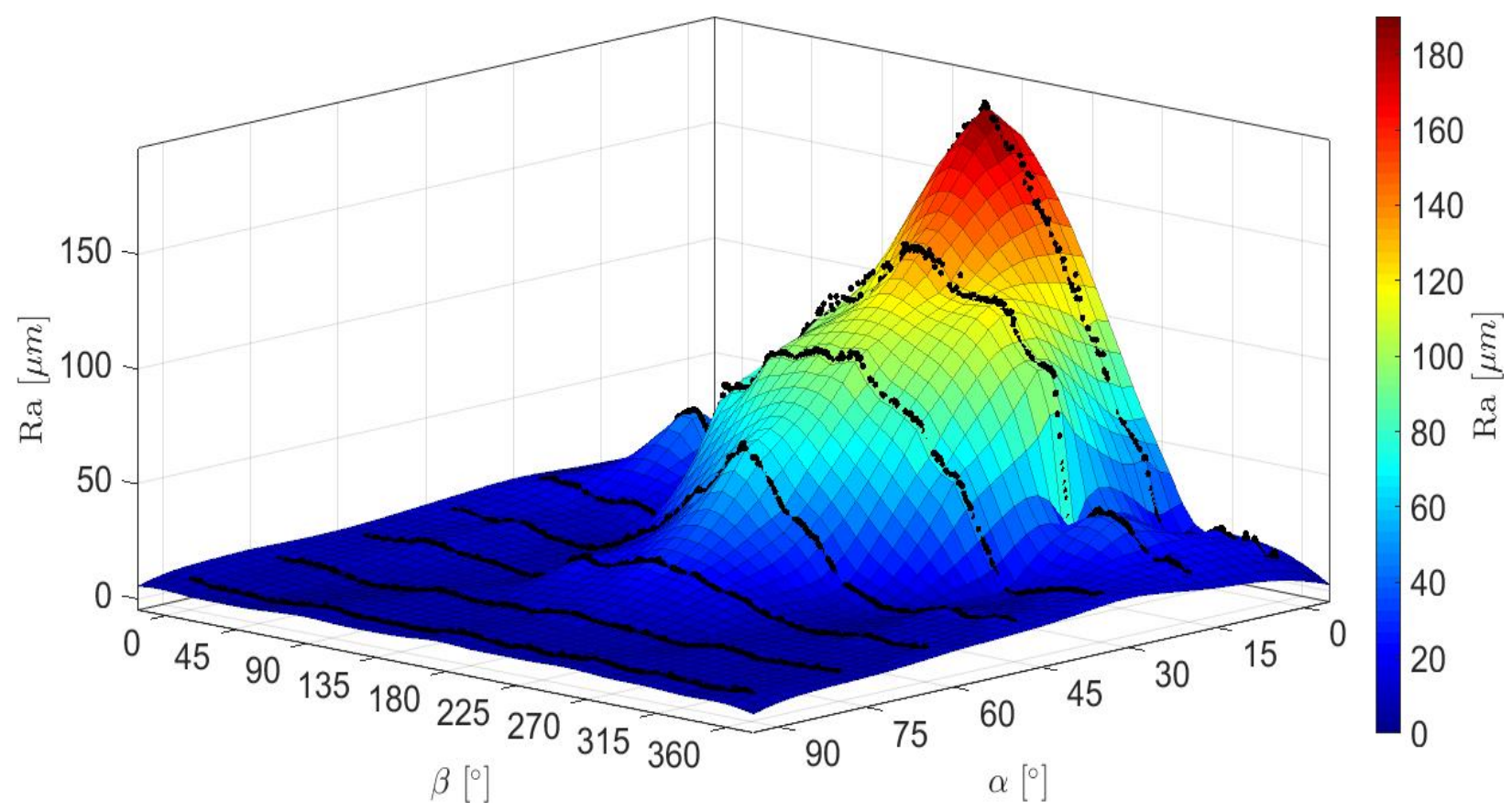

(a)

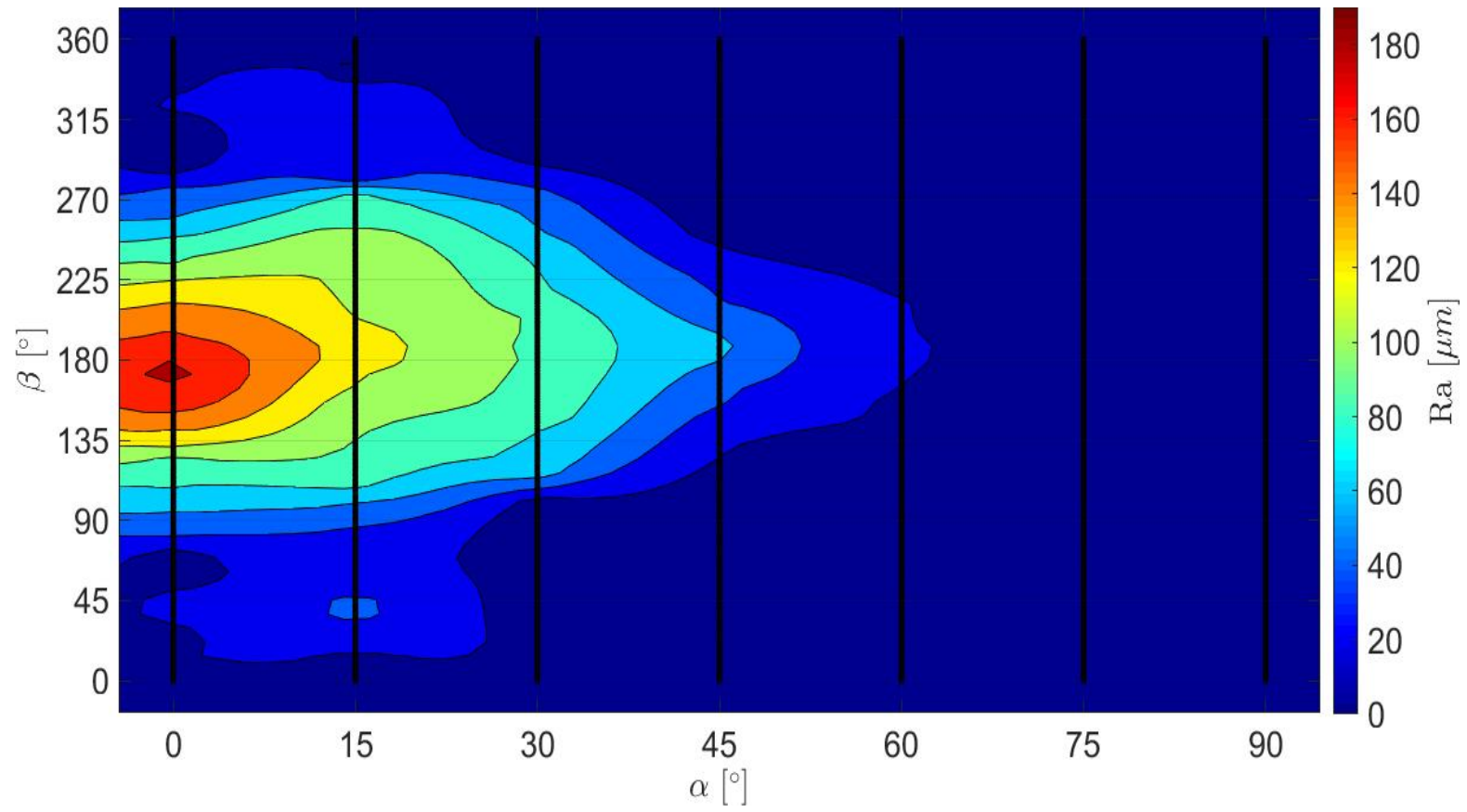

(b)

Figure 18: Biharmonic interpolated fit of the analyzed Ra-values as a function of $\alpha$ and $\beta$. (a) Surface plot. (b) Contour plot. 


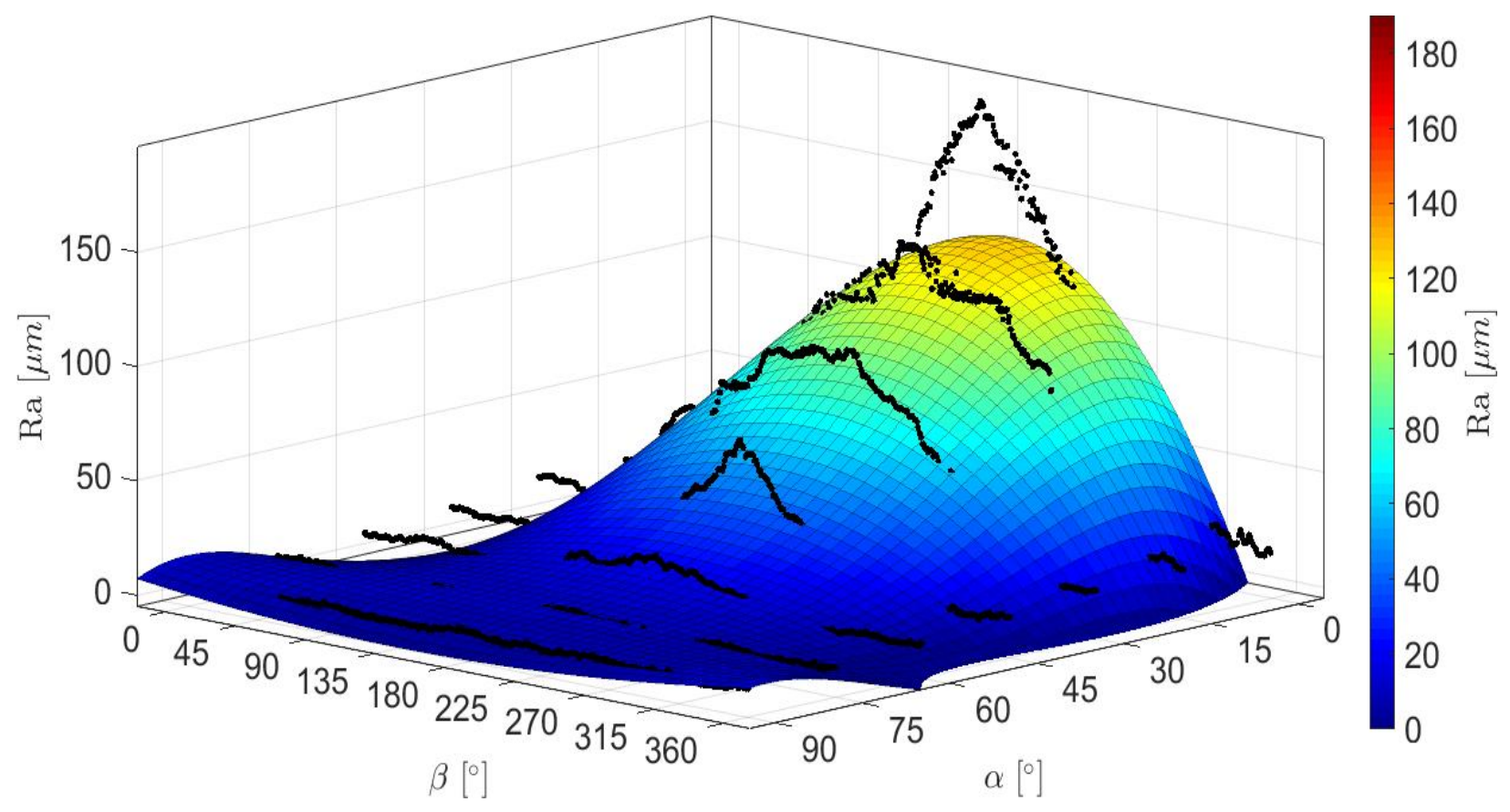

(a)

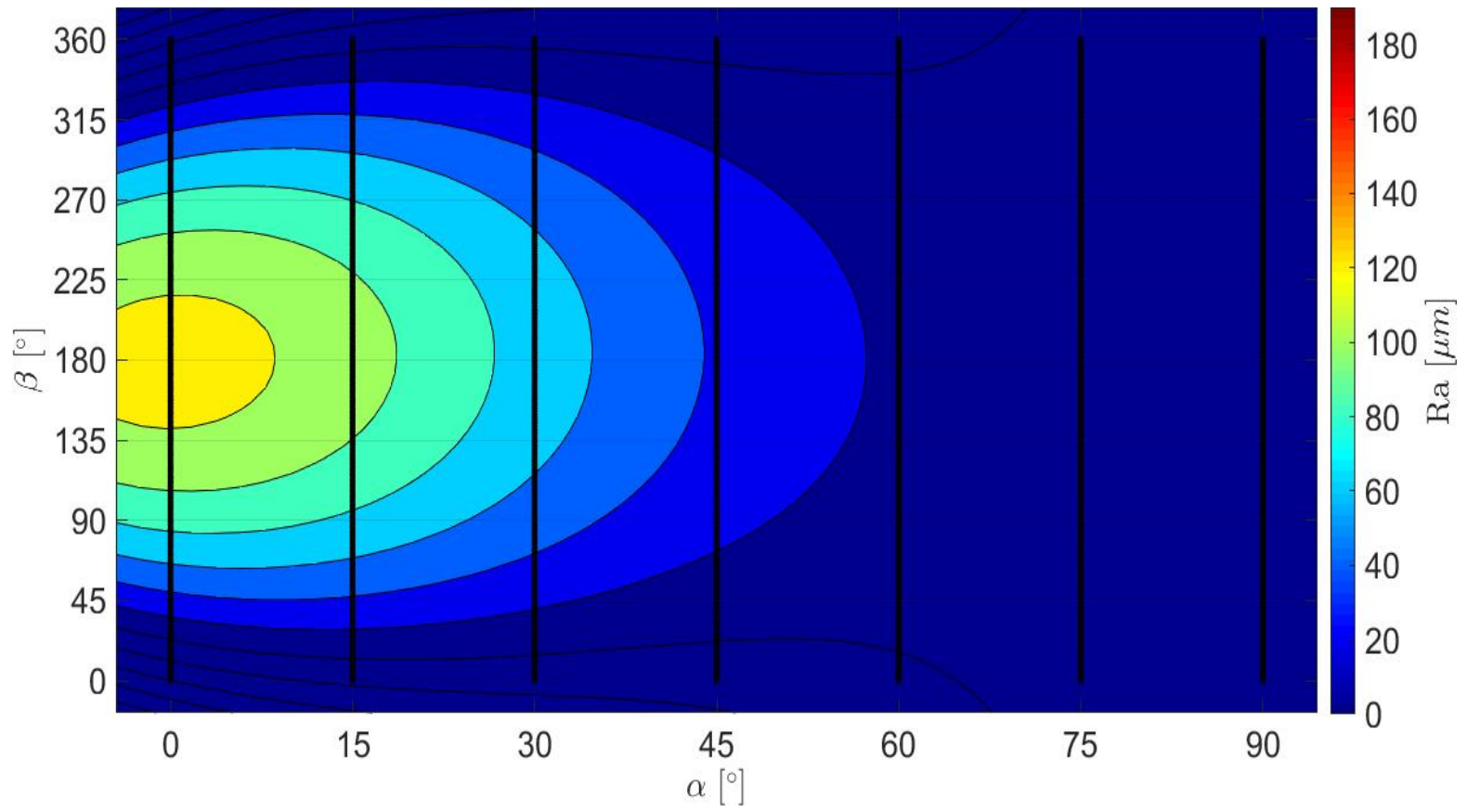

(b)

Figure 19: Polynomial fit of the analyzed Ra-values as a function of $\alpha$ and $\beta$. (a) Surface plot. (b) Contour plot. 
520 One of the main reasons identified for the poor fit was the bumps observed around $\beta=$ $52145^{\circ}$ and $\beta=315^{\circ}$. Therefore it was decided to isolate the $\beta$ range where the rough 522 regions began (i.e. in the range of $\beta=80^{\circ}$ and $\beta=280^{\circ}$ as seen in Fig. 15), resulting in 523 another polynomial fit for the selected $\beta$-range. The surface plot and contour plot of the 524 new polynomial fit can be seen in Fig. 20 and the corresponding model equation was: $R a(\alpha, \beta)=-276.9+4.783 \times \alpha+4.856 \times \beta-0.08222 \times \alpha^{2}-0.06836 \times \alpha \times \beta-$

The new fitting yielded an $R^{2}$ of 0.967 . As seen in Fig. 20(a), the surface prediction plot 532 has better agreement with the interpolated plot shown in Fig. 18(a). A comparison of the maximum values observed in the contour plots shown in Fig. 20(b) and 18(b), highlights

534 the ability of the model to better capture the high Ra-values as compared to the 535 previous polynomial model. However, the deviation between predicted and measured maximum $\mathrm{Ra}$ for $\alpha=0^{\circ}$ was still $\sim 15 \%$.

537 The produced polynomial fit with the corresponding model equation shown in equation (4) represented an adequate way of predicting Ra-values as a function of $\alpha$ and $\beta$ in the intervals $0^{\circ} \leq \alpha \leq 90^{\circ}$ and $80^{\circ} \leq \beta \leq 280^{\circ}$ for channels made in similar dimensions, in the 540 same material, and under similar manufacturing conditions. For fully encompassing 541 response surface models, it would be more accurate to work with statistical methods 542 such as bootstrapping or Bayesian statistics, but this was beyond the focus of the 543 current study. 


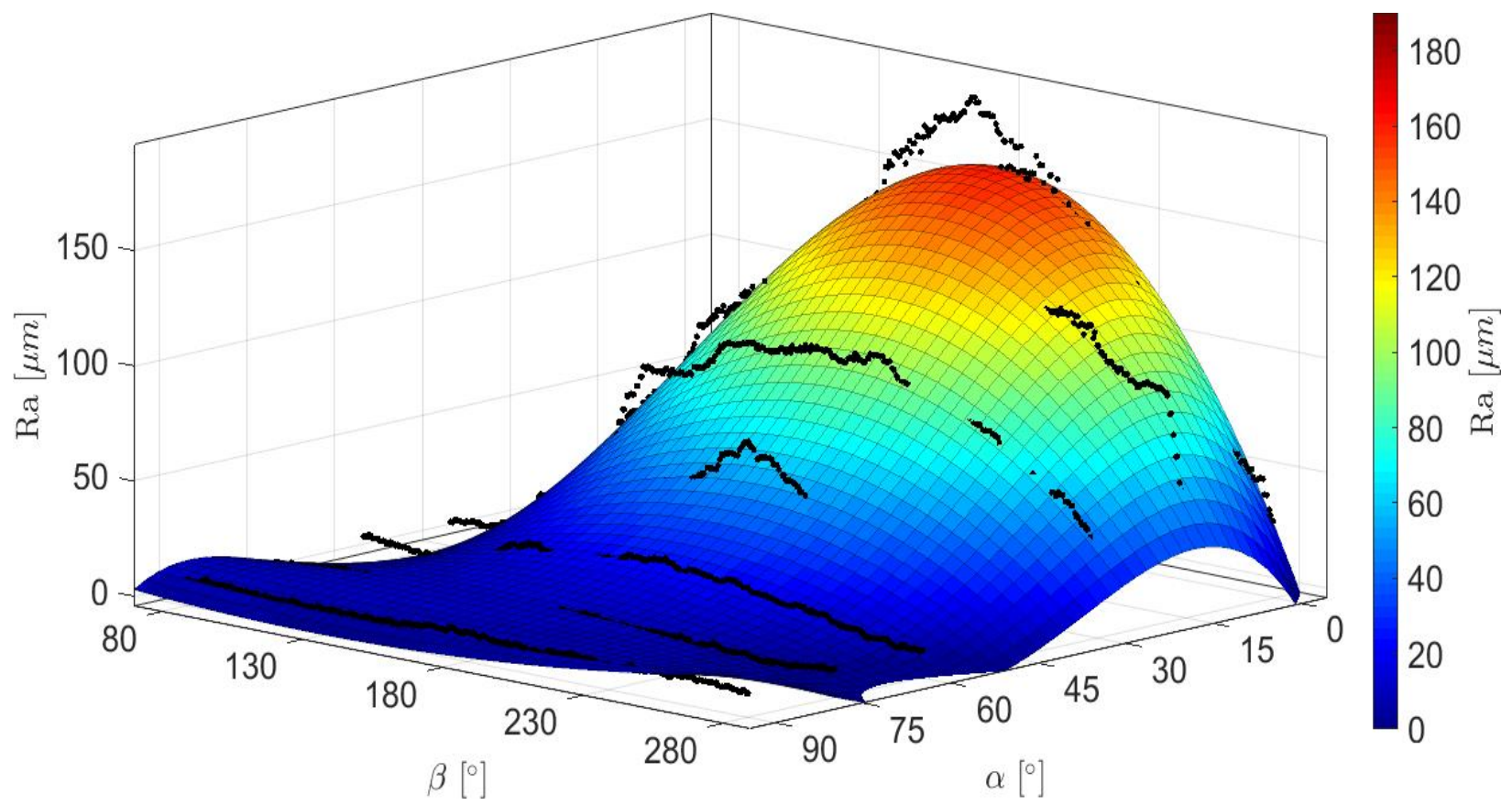

(a)

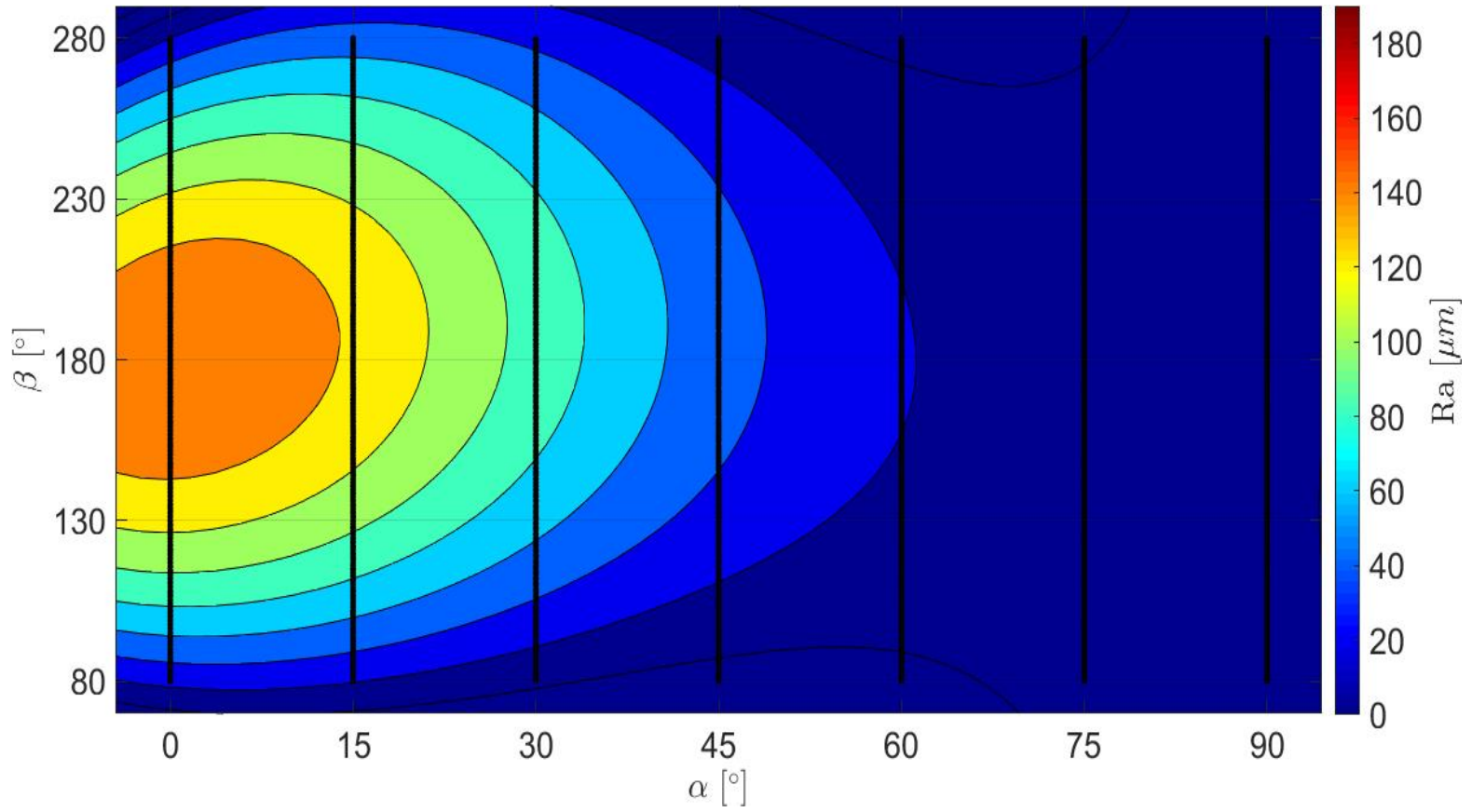

(b)

Figure 20: Polynomial fit of the reduced $\beta$-range of the analyzed Ra-values as a function of $\alpha$ and $\beta$. (a) Surface plot. (b) Contour plot. 
554

Table 3 shows Ra-values obtained by utilizing equation (4) for a case where a $\mathrm{D}=2 \mathrm{~mm}$ channel was produced at $\alpha=25^{\circ}$. The $\mathrm{Ra} / \mathrm{D}$ values, corresponding friction factor values, and the subsequently calculated local Nusselt numbers for five different $\beta$ orientations are also shown in Table 3.

Table 3: Nusselt number estimates, dependent on the local orientation $\beta$ with $\alpha=25^{\circ}$.

\begin{tabular}{|l|l|l|l|l|}
\hline $\boldsymbol{\beta}\left[^{\left.{ }^{\circ}\right]}\right.$ & $\mathbf{R a}(\boldsymbol{\alpha}, \boldsymbol{\beta})[\boldsymbol{\mu m}]$ & $\mathbf{R a} / \mathbf{D}[-]$ & $\mathbf{f}[-]$ & Nud $[-]$ \\
\hline 80 & 9.4 & 0.0047 & 0.034 & 136.6 \\
\hline 105 & 49.3 & 0.0246 & 0.057 & 198.4 \\
\hline 130 & 78.9 & 0.0394 & 0.065 & 217.5 \\
\hline 155 & 98.3 & 0.0492 & 0.072 & 233.6 \\
\hline 180 & 107.5 & 0.0537 & 0.077 & 244.7 \\
\hline
\end{tabular}

Under the selected conditions in Table 3, the calculated local Nusselt number changed by nearly a factor of 2 from $\beta=80^{\circ}$ to $\beta=180^{\circ}$ highlighting a significant influence of the local roughness characteristics. The current work thus enabled the prediction of the local heat transfer ability in a channel as a function of the design parameters $\alpha$ and $\beta$ (in the ranges of $0^{\circ} \leq \alpha \leq 90^{\circ}$ and $80^{\circ} \leq \beta \leq 280^{\circ}$ ) via the prediction of local roughness.

The current Nusselt number estimates suggest that an increase in surface roughness will lead to an increase in heat transfer. However, the increased roughness observed in the current work is correlated to a decrease in the effective hydraulic diameter due to the added dross material [26]. A reduction in the hydraulic diameter will typically result in an increased pressure drop and/or a decreased mass flow (depending on the control mechanism for the hydraulic device maintaining the flow) - potentially causing a decrease in heat transfer. The two effects on heat transfer are counteractive and their relative dominance will be investigated in future work 


\section{Conclusion}

570 This work presented a new methodology for linking X-ray CT and complete roughness

571 characterization of metal AM channels together with a corresponding application case.

572 The purpose of the methodology was to enable the generation of models for local

573 roughness prediction. This type of model would allow for the prediction of roughness in

574 channels made by the same system, in the same material, under the same process

575 parameters, and in similar dimensions as the channels used to generate the model.

576 Such a model could be used either in the design phase of metal AM components or for performance modeling. The work utilized and built upon a novel methodology for general surface analysis of channels using X-ray CT and image analysis. The presented methodology enabled 3D roughness information to be acquired nondestructively from the inner surfaces of the investigated channels, giving a full characterization of the channel roughness.

582 Two orientation angles $\alpha$ and $\beta$ (or global and local orientation respectively) were defined in this work in order to describe the local roughness observed. A novel method for extracting roughness profiles from 3D deviation data representing straight channel geometries was also presented. The results showed that the proposed methodology was able to extract representing roughness profiles from the obtained 3D deviation data.

As an application case, an analysis of seven LPBF manufactured channels built at different $\alpha$-orientations was performed. The investigation confirmed that the $\mathrm{Ra}$ roughness was highly dependent on both the global and the local orientation. Although these results were expected, the full $360^{\circ}$ roughness characterization enabled a detailed and quantifiable description of the observed roughness, its distribution and the

593 influence of orientation on the local roughness. The highest Ra-values were found at 594 low $\alpha$-values and $\beta$-values of approximately $180^{\circ}$, corresponding to the top point of the overhanging area inside the channels. The concept of a rough belt with an angular width was introduced, and the results showed that the angular width was directly related

597 to the a-orientation. However, no significant differences were found between the two 598 orientations $\alpha=75^{\circ}$ and $\alpha=90^{\circ}$ due to the large voxel size obtained from the X-ray CT 
599 procedure. Furthermore, the influence of staircase effects was discussed and shown as 600 a possible explanation for rough tracks observed at approximately $\beta=45^{\circ}$ and $\beta=315^{\circ}$ 601 for both $\alpha=0^{\circ}$ and $\alpha=15^{\circ}$.

602 A simple polynomial prediction model was obtained using a curve-fitting technique that 603 allowed for the prediction of the Ra-values within the orientation intervals of $0^{\circ} \leq \alpha \leq 90^{\circ}$ 604 and $80^{\circ} \leq \beta \leq 280^{\circ}$. However, the model showed that polynomial modeling may not be 605 enough for adequately capturing the relatively high roughness observed at around $\beta=$ $606180^{\circ}$.

607 Utilizing the obtained model, the influence of the local roughness on the local Nusselt 608 number was evaluated. It was found that the Nusselt number almost doubled over the 609 investigated $\beta$-interval in the selected case study. This illustrated the importance of 610 adequately characterizing the local surface roughness and accounting for the local 611 Nusselt number when designing cooling channels.

612 Results from the current study suggested that the internal roughness of freeform shapes 613 should not be characterized by single or few global measurements only. Instead, a 614 complete $360^{\circ}$ characterization of channels is necessary due to the multiple orientation 615 dependency of the observed channel roughness. The current study presents a novel 616 methodology and tool for such a characterization and demonstrates its importance in 617 prediction and performance modeling by applying the methodology to a case study.

618 Future work should look into the development of the profile generation technique to 619 account for an incrementally increasing angular criterion, thus generating more 620 accurately representing roughness profiles. The application of statistical methods for the 621 generation of more accurate predictive models of the Ra-values should be investigated.

622 Finally, the use of the acquired prediction models for flow simulation purposes is seen 623 as a natural next step.

624 Even though it was not the intention of the current work to challenge existing standards, 625 the proposed methodology and subsequently presented case study results may indicate 626 the need for improvements or additions to the current standards. Such that the design of 627 freeform geometries is more clearly part of the scope of the standards. 
Overall, this work is envisioned to lead towards tools that enable the generation of component-specific prediction models. Specifically, in applications such as conformal cooling channels where high roughness cannot be avoided by following conventional design guidelines. This will aid in the pursuit of more accurate simulations for the performance of LPBF manufactured channels.

\section{Acknowledgments}

Funding: This work was supported by the Innovation Fund Denmark Grand Solutions project "MADE Digital" [grant no. 6151-000068]; Sina Baier is grateful for financial support from Innovation Fund Denmark [grant no. 5152-00005B].

The 3D Imaging Center at The Technical University of Denmark is gratefully acknowledged for their support on X-ray computed tomography acquisition.

\section{References}

[1] M.K. Thompson, G. Moroni, T. Vaneker, G. Fadel, R.I. Campbell, I. Gibson, A. Bernard, J. Schulz, P. Graf, B. Ahuja, F. Martina, Design for Additive Manufacturing: Trends, opportunities, considerations, and constraints, CIRP Ann. - Manuf. Technol. 65 (2016) 737-760. doi:10.1016/j.cirp.2016.05.004.

[2] V. Petrovic, J. Vicente Haro Gonzalez, O. Jordá Ferrando, J. Delgado Gordillo, J. Ramon Blasco Puchades, L. Portoles Grinan, Additive layered manufacturing: Sectors of industrial application shown through case studies, Int. J. Prod. Res. 49 (2011) 1061-1079. doi:10.1080/00207540903479786.

[3] M.S. Shinde, K.M. Ashtankar, Additive manufacturing-assisted conformal cooling channels in mold manufacturing processes, Adv. Mech. Eng. 9 (2017) 1-14. doi:10.1177/1687814017699764.

[4] D. Wang, S. Mai, D. Xiao, Y. Yang, Surface quality of the curved overhanging structure manufactured from 316-L stainless steel by SLM, Int. J. Adv. Manuf. Technol. 86 (2016) 781-792. doi:10.1007/s00170-015-8216-6.

[5] A. Charles, A. Elkaseer, L. Thijs, V. Hagenmeyer, S. Scholz, Effect of process 
parameters on the generated surface roughness of down-facing surfaces in selective laser melting, Appl. Sci. 9 (2019). doi:10.3390/app9061256.

[6] E.S.A. Nasr, A. Al-Ahmari, K. Moiduddin, CAD Issues in Additive Manufacturing, in: Compr. Mater. Process., Elsevier, 2014: pp. 375-399. doi:10.1016/B978-0-08096532-1.01015-3.

[7] A. Triantaphyllou, C.L. Giusca, G.D. Macaulay, F. Roerig, M. Hoebel, R.K. Leach, B. Tomita, K.A. Milne, Surface texture measurement for additive manufacturing, Surf. Topogr. Metrol. Prop. 3 (2015) 1-8. doi:10.1088/2051-672X/3/2/024002.

[8] Q. Han, H. Gu, S. Soe, R. Setchi, F. Lacan, J. Hill, Manufacturability of AlSi10Mg overhang structures fabricated by laser powder bed fusion, Mater. Des. 160 (2018) 1080-1095. doi:10.1016/j.matdes.2018.10.043.

[9] H. Chen, D. Gu, J. Xiong, M. Xia, Improving additive manufacturing processability of hard-to-process overhanging structure by selective laser melting, J. Mater. Process. Technol. 250 (2017) 99-108. doi:10.1016/j.jmatprotec.2017.06.044.

[10] J.C. Fox, S.P. Moylan, B.M. Lane, Effect of Process Parameters on the Surface Roughness of Overhanging Structures in Laser Powder Bed Fusion Additive Manufacturing, in: Procedia CIRP, 2016: pp. 131-134. doi:10.1016/j.procir.2016.02.347.

[11] J.C. Snyder, C.K. Stimpson, K.A. Thole, D. Mongillo, Build Direction Effects on Additively Manufactured Channels, J. Turbomach. 138 (2016) 1-8. doi:10.1115/GT2015-43935.

[12] The Association of German Engineers, VDI 3405 Part 3: Additive manufacturing processes, rapid manufacturing - Design rules for part production using laser sintering and laser beam melting, (2015) 32.

[13] International Organization for Standardization, ISO 25178-2:2012: Geometrical product specifications (GPS) - Surface texture: Areal - Part 2: Terms, definitions and surface texture parameters, (2012).

[14] A. Townsend, N. Senin, L. Blunt, R.K. Leach, J.S. Taylor, Surface texture 
metrology for metal additive manufacturing: a review, Precis. Eng. 46 (2016) 3447. doi:10.1016/j.precisioneng.2016.06.001.

[15] S. Carmignato, W. Dewulf, R. Leach, Industrial X-ray computed tomography, Springer, 2017. doi:10.1007/978-3-319-59573-3.

[16] A. du Plessis, P. Sperling, A. Beerlink, O. Kruger, L. Tshabalala, S. Hoosain, S.G. le Roux, Standard method for microCT-based additive manufacturing quality control 3: Surface roughness, MethodsX. 5 (2018) 1111-1116. doi:10.1016/j.mex.2018.09.004.

[17] X.J. Jiang, D.J. Whitehouse, Technological shifts in surface metrology, CIRP Ann. - Manuf. Technol. 61 (2012) 815-836. doi:10.1016/j.cirp.2012.05.009.

[18] A. du Plessis, I. Yadroitsev, I. Yadroitsava, S.G. Le Roux, X-Ray Microcomputed Tomography in Additive Manufacturing: A Review of the Current Technology and Applications, 3D Print. Addit. Manuf. 5 (2018) 227-247. doi:10.1089/3dp.2018.0060.

[19] J.P. Kruth, M. Bartscher, S. Carmignato, R. Schmitt, L. De Chiffre, A. Weckenmann, Computed tomography for dimensional metrology, CIRP Ann. Manuf. Technol. 60 (2011) 821-842. doi:10.1016/j.cirp.2011.05.006.

[20] T. Vorburger, Optical Methods of Surface Measurement, NIST, Gaithersburg, MD, 2012.

[21] M. Dadkhah, M. Peglow, E. Tsotsas, Characterization of the internal morphology of agglomerates produced in a spray fluidized bed by X-ray tomography, Powder Technol. 228 (2012) 349-358. doi:10.1016/j.powtec.2012.05.051.

[22] R. Pashminehazar, A. Kharaghani, E. Tsotsas, Determination of fractal dimension and prefactor of agglomerates with irregular structure, Powder Technol. 343 (2019) 765-774. doi:10.1016/j.powtec.2018.10.046.

[23] International Organization for Standardization, ISO 4288:1998: Geometrical product specifications (GPS) - Surface texture: Profile method - Rules and procedures for the assessment of surface texture, (1998). 
711

712

713

714

715

716

717

718

719

720

721

722

723

724

725

726

727

728

729

730

731

732

733

734

735

736

737

738

[24] C.K. Stimpson, J.C. Snyder, K.A. Thole, Roughness Effects on Flow and Heat Transfer for Additively Manufactured Channels, in: Proc. ASME Turbo Expo 2015 Turbine Tech. Conf. Expo., 2015: pp. 1-13. http://asmedigitalcollection.asme.org/.

[25] E.A.M. Elshafei, M.M. Awad, E. El-Negiry, A.G. Ali, Heat transfer and pressure drop in corrugated channels, Energy. 35 (2010) 101-110. doi:10.1016/j.energy.2009.08.031.

[26] T. Dahmen, C.G. Klingaa, S. Baier, D.B. Pedersen, J.H. Hattel, Methodology for geometric characterization and dimensioning of additively manufactured channels, in: Proc. Jt. Spec. Interes. Gr. Meet. between Euspen ASPE Adv. Precis. Addit. Manuf. (2019)., The European Society for Precision Engineering and Nanotechnology, 2019. www.euspen.eu (accessed November 6, 2019).

[27] H. Herwig, What Exactly Is the Nusselt Number in Convective Heat Transfer Problems and Are There Alternatives?, Entropy. 18 (2016) 1-15. doi:10.3390/e18050198.

[28] V. Gnielinski, New equation for heat and mass transfer in turbulent pipe and channel flow, Int Chem Eng. 16 (1976) 359-363.

[29] G. Takacs, Sucker-rod pumping handbook, Gulf Professional Publishing, 2015.

[30] M. Harcarik, R. Jankovych, Relationship Between Values of Profile and Areal Surface Texture Parameters, MM Sci. J. 2016 (2016) 1659-1662. doi:10.17973/mmsj.2016_12_2016206.

[31] F. Blateyron, The Areal Field Parameters, in: R.K. Leach (Ed.), Characterisation Areal Surf. Texture, Springer, 2013: pp. 15-43. doi:10.1007/978-3-642-364587_2.

[32] International Organization for Standardization, ISO 4287:1997: Geometrical product specifications (GPS) - Surface texture: Profile method - Terms, definitions and surface texture parameters, (1997).

[33] C.G. Klingaa, M.K. Bjerre, S. Baier, L. De Chiffre, S. Mohanty, J.H. Hattel, Roughness Investigation of SLM Manufactured Conformal Cooling Channels 
Using X-ray Computed Tomography, E-Journal Nondestruct. Test. (2019). https://www.ndt.net/search/docs.php3?showForm=off\&id=23739.

[34] T. Lewiner, H. Lopes, Efficient implementation of Marching Cubes ' cases with topological guarantees, J. Graph. Tools. 8 (2003) 1-8.

[35] J.P. Bons, A Review of Surface Roughness Effects in Gas Turbines, J. Turbomach. 132 (2010) 021004. doi:10.1115/1.3066315.

[36] L.F. Moody, Friction Factors for Pipe Flow, Trans. Am. Soc. Mech. Eng. 66 (1944) 671-681.

[37] G. Wilkinson, Water Properties, in: A-to-Z Guid. to Thermodyn. Heat Mass Transf. Fluids Eng. Online, Begellhouse, 2011. doi:10.1615/AtoZ.w.water_properties.

[38] F. Zanini, E. Sbettega, M. Sorgato, S. Carmignato, New Approach for Verifying the Accuracy of X-ray Computed Tomography Measurements of Surface Topographies in Additively Manufactured Metal Parts, J. Nondestruct. Eval. 38 (2019). doi:10.1007/s10921-018-0547-4.

[39] S. Carmignato, V. Aloisi, F. Medeossi, F. Zanini, E. Savio, Influence of surface roughness on computed tomography dimensional measurements, CIRP Ann. Manuf. Technol. 66 (2017) 499-502. doi:10.1016/j.cirp.2017.04.067.

[40] L. De Chiffre, S. Carmignato, J.P. Kruth, R. Schmitt, A. Weckenmann, Industrial applications of computed tomography, CIRP Ann. - Manuf. Technol. 63 (2014) 655-677. doi:10.1016/j.cirp.2014.05.011. 